\title{
Air-gap membrane distillation as a one-step process for textile wastewater treatment
}

DOI:

10.1016/j.cej.2018.10.209

\section{Document Version}

Accepted author manuscript

Link to publication record in Manchester Research Explorer

\section{Citation for published version (APA):}

Leaper, S., Abdel-karim, A., Gad-allah, T. A., \& Gorgojo, P. (2018). Air-gap membrane distillation as a one-step process for textile wastewater treatment. Chemical Engineering Journal. https://doi.org/10.1016/j.cej.2018.10.209

\section{Published in:}

Chemical Engineering Journal

\section{Citing this paper}

Please note that where the full-text provided on Manchester Research Explorer is the Author Accepted Manuscript or Proof version this may differ from the final Published version. If citing, it is advised that you check and use the publisher's definitive version.

\section{General rights}

Copyright and moral rights for the publications made accessible in the Research Explorer are retained by the authors and/or other copyright owners and it is a condition of accessing publications that users recognise and abide by the legal requirements associated with these rights.

\section{Takedown policy}

If you believe that this document breaches copyright please refer to the University of Manchester's Takedown Procedures [http://man.ac.uk/04Y6Bo] or contact uml.scholarlycommunications@manchester.ac.uk providing relevant details, so we can investigate your claim.

\section{OPEN ACCESS}




\section{Accepted Manuscript}

Air-gap membrane distillation as a one-step process for textile wastewater treatment

Sebastian Leaper, Ahmed Abdel-Karim, Tarek A. Gad-Allah, Patricia Gorgojo

PII:

S1385-8947(18)32169-7

DOI:

https://doi.org/10.1016/j.cej.2018.10.209

Reference:

CEJ 20272

To appear in:

\section{Chemical Engineering Journal}

Received Date: $\quad 14$ August 2018

Revised Date: $\quad 9$ October 2018

Accepted Date: $\quad 28$ October 2018

Please cite this article as: S. Leaper, A. Abdel-Karim, T.A. Gad-Allah, P. Gorgojo, Air-gap membrane distillation as a one-step process for textile wastewater treatment, Chemical Engineering Journal (2018), doi: https://doi.org/ 10.1016/j.cej.2018.10.209

This is a PDF file of an unedited manuscript that has been accepted for publication. As a service to our customers we are providing this early version of the manuscript. The manuscript will undergo copyediting, typesetting, and review of the resulting proof before it is published in its final form. Please note that during the production process errors may be discovered which could affect the content, and all legal disclaimers that apply to the journal pertain. 


\title{
Air-gap membrane distillation as a one-step process for textile wastewater treatment
}

\author{
Sebastian Leaper ${ }^{1 *}$, Ahmed Abdel-Karim ${ }^{1,2 *}$, Tarek A. Gad-Allah², Patricia Gorgojo ${ }^{1}$ \\ ${ }^{1}$ School of Chemical Engineering and Analytical Science, The University of Manchester, Oxford
} Road, Manchester M13 9PL, UK.

${ }^{2}$ Water Pollution Research Department, National Research Centre, 33 EL Bohouth St. (former EL Tahrir St.), P.O. 12622, Dokki, Giza, Egypt.

* Both authors contributed equally to this work

Corresponding author: p.gorgojo@manchester.ac.uk, tel: +44 (0) 161-30-64395

\section{Abstract}

Wastewater from textile dyeing plants contains a complex mixture of dyes, salts, surfactants and other additives which make it challenging to treat and harmful to release directly into the water system. Current treatment technologies are composed of many steps, increasing the cost and complexity of water management. Air gap membrane distillation (AGMD) is a versatile water treatment process which has potential to reduce the complexity of textile dyeing wastewater but has not yet been investigated for this application. In this work, we used commercial polytetrafluoroethylene (PTFE) membranes in AGMD to recover pure water from simulated textile wastewater containing $\mathrm{NaCl}$ and either sunset yellow (SY) or rose bengal (RB) dyes and sodium dodecyle sulfate (SDS) surfactant. 100\% salt and colour removal was achieved for binary feed solutions $(\mathrm{NaCl}+\mathrm{SY}$ or $\mathrm{RB})$ over $20 \mathrm{~h}$ of testing, whilst maintaining stable fluxes between 11.7 and $12.6 \mathrm{~L} \mathrm{~m}^{-2} \mathrm{~h}^{-1}(\mathrm{LMH})$ throughout. After 24 $\mathrm{h}$ of continuous testing of the ternary feed solution $(\mathrm{NaCl}+\mathrm{RB}+\mathrm{SDS})$ the flux was as high as $11 \mathrm{LMH}$ with permeate conductivity less than $50 \mu \mathrm{S} \mathrm{cm} \mathrm{cm}^{-1}$. However after $70 \mathrm{~h}$ these had reached $\sim 3 \mathrm{LMH}$ and $421.8 \mu \mathrm{S} \mathrm{cm}^{-1}$, respectively indicating a need for cleaning or back- 
flushing between batches. Parallel direct contact membrane distillation (DCMD) tests achieved lower colour and total carbon removal after just 8 hours of testing with the ternary feed solution. Comparisons between our tests and those found in the literature are made and indicate that AGMD may be the most suitable configuration for this application due to reduced flux decline and potentially higher thermal efficiency.

Keywords: air gap membrane distillation (AGMD); membrane fouling; PTFE membrane; textile wastewater.

\section{Highlights}

1. Synthetic textile wastewater was purified by air gap membrane distillation (AGMD)

2. AGMD simultaneously removed all salts, surfactants and dyes in a single process

3. Permeate quality remained high after 70 hours of continuous testing

\section{Introduction}

Producing 1 tonne of textile materials requires approximately 300 tonnes of water $[1,2]$. This makes the textile industry one of the thirstiest in the world and yet it is largely concentrated in regions which can suffer from severe water scarcity, particularly China and India [3]. Furthermore, the wastewater generated from textile mills can pose serious environmental risks due to the presence of harmful substances such as azo dyes, heavy metals, surfactants, salts and others [4-7]. The release of dyes into water streams can inhibit photosynthetic processes in aquatic organisms by reducing the amount of available sunlight that can be absorbed. Meanwhile, azo dyes and their secondary products have been shown to have mutagenic and carcinogenic effects, posing risks to humans and aquatic life alike [8]. In addition, depending on the nature of the dyeing process and variations in production schedules, the wastewater may be acidic or it may be alkaline [9]. The great variety of characteristics that textile wastewater can embody makes it challenging to find a single process suited to treating it all. In order to help secure water resources and reduce the 
detrimental effect of releasing the wastewater into the environment, the industry is opting to utilise increasingly sophisticated water treatment technologies. These typically include multistage processes such as biological/electrochemical/physico-chemical pre-treatment, coagulation/flocculation, sand filtration, membrane treatment and possibly end with multieffect evaporators or incineration for zero liquid discharge $[4,5,10,11]$. Together, these make up a highly complex water treatment process which can be expensive, energy intensive and highly space consuming [12]. In addition, the conventional filtration processes used such as ultrafiltration (UF), nanofiltration (NF) and reverse osmosis (RO) require these multiple pre-treatment steps in order to extend the time by which the membrane pores become blocked or fouled. The relatively high transmembrane pressure that is applied in these processes can lead to rapid pore blocking, extensive concentration polarisation and reduced permeate flux values even with appropriate pre-treatment steps [13-15].

One potential route to simplifying this process is by using membrane distillation (MD). This is a vapour pressure-driven separation process in which a liquid feed stream with an elevated temperature is passed across a hydrophobic membrane with a mean pore size much larger in comparison not only to the species that go through the membrane but also the species that are retained. Mean pore size values are typically in the range of $0.1-1 \mu \mathrm{m}$ with porosity values of $70-80 \%$ [16]. On the other side of the membrane there can be a cooler stream of pure water (either static or circulated), an applied vacuum, a flow of inert gas or an air-gap separating the membrane from a condensing surface. In each case, the vapour pressure difference across the membrane creates a driving force for vapour diffusion while the hydrophobicity of the membrane prevents liquid intrusion (phenomenon known as porewetting). This process can be used to remove inorganic non-volatile species from feed streams with a theoretical removal efficiency of $100 \%[16,17]$ and suffers less from 
concentration polarisation and membrane fouling than conventional pressure-driven filtration processes as pressurization of the feed side is not require [18, 19].

Though the total energy consumption of the process is higher than other membrane-based separation processes, it is a simple but effective method of recycling water in situations where a thermal energy source is already available (such as waste heat, ocean thermal gradients or in textile water effluent) [20]. Also, the use of membranes can reduce the vapour spaces that are required for conventional distillation processes and allow for operating temperatures that are well below the boiling point of water, even at atmospheric pressure. This, coupled with the lower operating pressures than typical filtration processes, means MD can be more compact, can be constructed out of cheaper polymeric materials and have potentially lower capital costs than alternative technologies [21]. MD has so far largely been studied for the treatment of highly saline water streams (such as seawater or RO brines) but there is increasing research into its suitability for treating various kinds of wastewater, for such applications as the extraction of pharmaceutical products and rare-earth metals [22, 23]. Despite the promise of this technology, relatively few papers have assessed its suitability to textile wastewater treatment. A recent review [24] revealed that research on the use of MD for this application was rising. However, many of the existing publications reported using single-component dye solutions as the feed water, free from salts and surfactants. It is well documented that the presence of surfactants can exacerbate the pore-wetting phenomenon due to hydrophobic-hydrophobic interactions resulting in their adhesion to the membrane surface. This can then create hydrophilic channels which can bridge the gap between the feed and permeate streams, reducing the rejection performance [25]. Therefore, testing multicomponent mixtures is critical for evaluating the true capabilities of this technology for this application. Furthermore, all but three studies identified [26-28] used the direct contact configuration, which, whilst being the simplest MD configuration, is known to suffer from 
conductive heat loss which increases its specific thermal energy consumption [29]. A lesserstudied configuration is air gap membrane distillation (AGMD) in which the permeate side consists of a small gap of stagnant air and a condensing surface which is cooled by a circulating fluid. Due to the insulating effect of the air gap, less heat is lost through conduction than with direct contact membrane distillation (DCMD). Furthermore, it is possible to recover the latent heat of condensation by using it to preheat the incoming feed water if used as the cooling fluid. This is the principle behind some larger scale systems such as Memstill ${ }^{\circledR}$ and can result in specific thermal and electrical energy consumptions as low as $72 \mathrm{kWh} / \mathrm{m}^{3}$ and $0.0278 \mathrm{kWh} / \mathrm{m}^{3}$, respectively [30, 31].

The high operating temperatures used in most textile dyeing mills means there is available waste heat which could be used to recycle water in one step via MD. To the best of our knowledge, no one has yet used the air gap configuration for textile wastewater treatment, despite it having higher thermal efficiency and often better performance at the pilot scale compared to other configurations $[32,33]$. Herein we assess the feasibility (in terms of flux and solute rejection) of using commercial PTFE membranes for the long-term treatment of multi-component synthetic textile wastewater via air-gap membrane distillation. The use of synthetic wastewater containing the predominant components of real wastewater, namely dyes, surfactants and salts, was chosen to avoid any unknown variability from real samples. This work can be used as a preliminary study against which further developments on membrane properties, cleaning protocols and performance with real wastewater can be compared.

\section{Experimental}

\subsection{Materials}

To simulate wastewater from the textile dyeing processes, aqueous mixtures of sodium chloride, sodium dodecyle sulfate surfactant (SDS) and two dyes, sunset yellow (SY) and 
rose bengal (RB), were prepared as the feed solutions for this work. The two tested dyes, which had molecular weights of 452.36 and $1017.65 \mathrm{~g} \mathrm{~mol}^{-1}$, respectively, were purchased from Sigma Aldrich, UK and their chemical structures are depicted in Fig. 1. SDS and $\mathrm{NaCl}$ $\left(99.5 \%, \mathrm{MW}=58.44 \mathrm{~g} \mathrm{~mol}^{-1}\right)$ were purchased from Sigma Aldrich and Acros Organics, respectively. The single-dye feed solutions were prepared at a concentration of $100 \mathrm{mg} \mathrm{L}^{-1}$ by dissolving appropriate amounts of the dye powders in deionised (DI) water. This chosen concentration is a good representation of real wastewater and is commonly used for synthetic solutions [34]. For the binary feed solution (dye + salt), $100 \mathrm{mg}$ of dye and $5 \mathrm{~g} \mathrm{NaCl}$ were added to $1 \mathrm{~L}$ of DI water and dissolved by magnetic stirring. For the ternary feed solution $($ dye + salt + surfactant), $100 \mathrm{mg}$ dye, $5 \mathrm{~g} \mathrm{NaCl}$ and $1 \mathrm{~g}$ SDS were added to $1 \mathrm{~L}$ of DI water and stirred continuously until all species had dissolved. Surfactant concentrations in textile wastewater may be around $500 \mathrm{mg} \mathrm{L}^{-1}[35]$ so our choice of $1 \mathrm{~g} \mathrm{~L}^{-1}$ was chosen as an extreme case.

a)

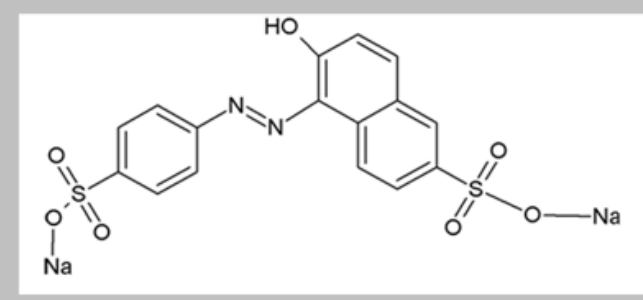

$\mathrm{C}_{16} \mathrm{H}_{10} \mathrm{~N}_{2} \mathrm{Na}_{4} \mathrm{O}_{7} \mathrm{~S}_{2}$ (MW: $452.36 \mathrm{~g} \mathrm{~mol}^{-1}$ ) b)<smiles>COC(=O)c1c(Cl)c(Cl)c(Cl)c(Cl)c1-c1c2cc(I)c(=O)c(I)c-2oc2c(I)c(O[Na])c(I)cc12</smiles>

$\mathrm{C}_{20} \mathrm{H}_{2} \mathrm{Cl}_{4} \mathrm{I}_{4} \mathrm{Na}_{2} \mathrm{O}_{5}$ (MW: $1,017.65 \mathrm{~g} \mathrm{~mol}^{-1}$ )

Fig. 1. Chemical structures of the dyes tested in this study: (a) sunset yellow and (b) rose Bengal. The figure was prepared using ChemSketch software.

Commercial hydrophobic flat sheet polytetrafluoroethylene (PTFE) membranes were purchased from Sterlitech, USA. The PTFE was laminated on to a polypropylene (PP) nonwoven backing layer and had a reported mean pore size of $0.20 \mu \mathrm{m}$. The thickness of the membranes was measured using a Mitutoyo IP65 micrometer and compared to the value given by the supplier. The characteristics of the membrane are summarised in Table 1. 


\subsection{Membrane characterization}

Surface images of the membranes were taken before and after AGMD tests using scanning electron microscopy (SEM) (QUANTA FEG250, USA) with an acceleration voltage of 20 $\mathrm{kV}$. For the surface images, different areas of the membranes were cut and mounted onto SEM stages using carbon tape. Before imaging, the samples were sputtered with platinum (5$6 \mathrm{~nm}$ Pt layer) using an MTM 10 Thickness Monitor (Cressington, USA) in order to make the samples conductive.

To further investigate and compare the chemical bonds in the virgin and fouled/used membranes, attenuated total reflectance Fourier transform infrared spectroscopy (ATR-FTIR) was employed. This was carried out in an Ids Nicolet Is5 instrument (Thermo Scientific, UK) using a Ge crystal over the wavenumber range of $650-4000 \mathrm{~cm}^{-1}$ and a step size of $0.5 \mathrm{~cm}^{-1}$. Capillary flow porometry (PoroLux ${ }^{\mathrm{TM}}$ 1000, POROMETER, Belgium) was utilised to analyse the mean pore size, pore size distribution (PSD), and bubble point pore size of the membranes. The gas-liquid displacement method was used with perfluoropolyether (Porefil 125 , surface tension $=15.88 \pm 0.03 \mathrm{mN} \mathrm{m}^{-1}$ ) as the wetting liquid and further details can be found in our previous work [36].

An optical tensiometer (Attension Theta, Biolin Scientific, UK) was used to assess the hydrophobicity of the membranes via the sessile drop method. This measurement was conducted by dropping DI water onto the membrane surfaces using a Hamilton microsyringe. For each measurement, the DI droplet was recorded for a total of $20 \mathrm{~s}$ at 30 frames per second, and the contact angle value was taken $10 \mathrm{~s}$ after the water droplet had touched the sample surface. All measurements were repeated 5 times and the values were presented as the mean \pm the standard deviation of the five values obtained.

\subsection{Air gap membrane distillation (AGMD)}


The AGMD tests in this work were carried out in an apparatus that has been previously described elsewhere [36]. A diagram of the setup is shown in Fig. 2. The membrane module had an air gap width of $3 \mathrm{~mm}$, which was the smallest value possible given the module design and materials used. During the experiments, the preheated feed solutions $\left(70{ }^{\circ} \mathrm{C}\right)$ were circulated at a rate of $380 \pm 5 \mathrm{~mL} \mathrm{~min}^{-1}$ using an Xcsource $12 \mathrm{~V}$ water pump with a flow control pinch valve (Sigma) connected to the $7 \mathrm{~mm}$ (outer diameter) silicon tubing used throughout. The feed was circulated through a custom-made Perspex membrane module containing silicon gaskets, a polycarbonate perforated membrane support disk and a polycarbonate membrane spacer disk which, together, defined the air gap width. On the permeate side, soft tap water which was cooled to $20{ }^{\circ} \mathrm{C}$ by a Julabo F12-ED chiller, was circulated behind a stainless steel condenser plate at a rate of $600 \pm 4 \mathrm{~mL} \mathrm{~min}^{-1}$. The volume of the feed solution was $2 \mathrm{~L}$ while the feed temperature was kept constant using a hot plate with a connected thermostat (MIL-C-17 ROHS, UK). The system was left to run for 60 min before measuring to allow sufficient time for conditioning. The permeate dripped out the of module by gravity and was collected in a measuring cylinder with a funnel placed below. The permeate volume was recorded every hour and the permeate flux $(J)$ was calculated using equation (1):

$$
J=\frac{V_{\mathrm{p}}}{A t}(1)
$$

where $V_{\mathrm{p}}$ is the volume of the permeate, $A$ is the membrane area and $t$ is the running time. The total membrane area was $28.27 \mathrm{~cm}^{2}$ whereas the effective area, due to the perforated membrane support was $7.16 \mathrm{~cm}^{2}$. However, to give more realistic values, the full membrane area was used in the flux calculations. Solute rejection $(S R)$ of the membranes was calculated as a percentage using equation (2):

$$
S R=\left(1-\frac{C_{\mathrm{P}}}{C_{\mathrm{F}}}\right) \times 100
$$


where $C_{\mathrm{P}}$ and $C_{\mathrm{F}}$ are the concentration of the solutes in the permeate and in the feed, respectively.

$\mathrm{NaCl}$ concentrations in the permeate were assessed in terms of the permeate conductivity, which was measured using a Fisher Scientific Accumet XL 200 conductivity meter from samples taken from the collection vessel every hour and then replaced. Dye concentrations were obtained via an ultraviolet-visible (UV-Vis) spectrophotometer (UV-2700, SHIMADZU, Japan). The initial and the final concentrations were determined using samples of the permeate and feed solutions at wavelengths of 490 , and $550 \mathrm{~nm}$ for SY, and RB dyes, respectively. Concentrations of SDS were analysed with a total organic carbon analyser TOC-V (Shimadzu-Japan) with total carbon content being measured and reported.

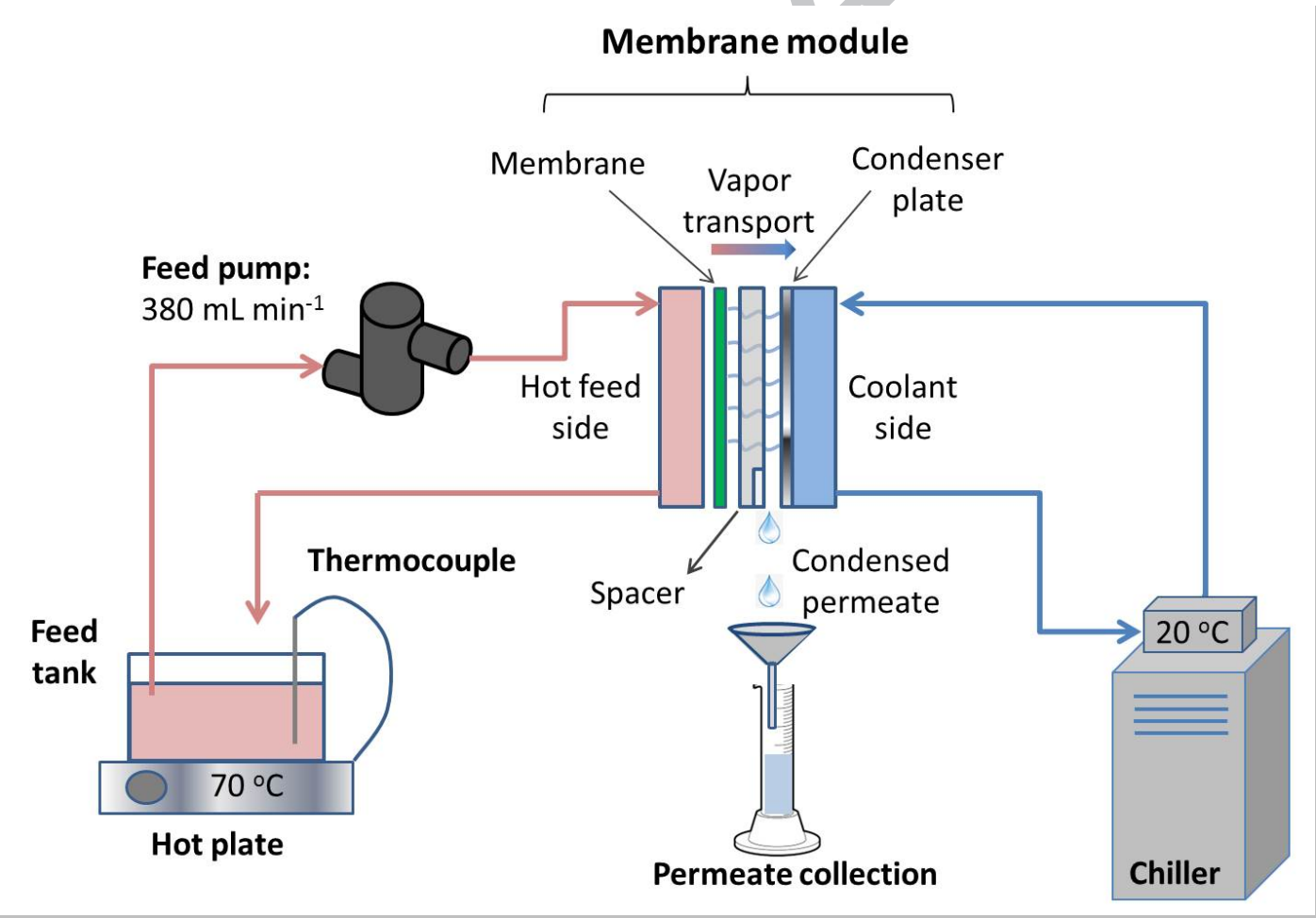

Fig. 2. Schematic representation of the air-gap membrane distillation system.

In order to compare the performance of AGMD with the more commonly used direct contact membrane distillation (DCMD), tests were performed using the latter configuration with the ternary solution of $\mathrm{RB}+\mathrm{NaCl}+\mathrm{SDS}$ as the feed. For this, the same membrane module was used but without the spacer or condenser plate and instead with an O-ring insert, ensuring a 
water-tight seal around the membrane. The hot feed was pumped through the module in the same way as for AGMD, again at $70{ }^{\circ} \mathrm{C}$. However, for the cold permeate stream, a $1 \mathrm{~L}$ jacketed vessel containing $300 \mathrm{~mL}$ of DI water was connected to the chiller, which circulated water around the vessel, set at $20^{\circ} \mathrm{C}$. A second pump was connected to the permeate side of the module with silicone tubing which was then placed into the jacketed vessel. Once the feed and permeate solutions had reached their set temperatures, the two pumps were switched on and began circulating the solutions across each side of the membrane. The feed flow rate was varied from 226, 380 and $1020 \pm 4 \mathrm{~mL} \mathrm{~min}^{-1}$ whereas the permeate flow rate was kept constant at $300 \pm 4 \mathrm{~mL} \mathrm{~min}^{-1}$. The change in mass was logged each hour using an Adam HCB 3001 weighing scale for a total of $8 \mathrm{~h}$ per test. In addition, approximately $9 \mathrm{~mL}$ of permeate was removed with a syringe each hour, and had its conductivity measured before being replaced back into the measuring cylinder. Permeate samples were also collected at the end of the experiments for total carbon measurements.

\section{Results and discussion}

\subsection{Membrane characterization}

An ideal membrane for MD applications should have high porosity $(>70 \%)$, a narrow pore size distribution, non-tortuous pores and a high contact angle $\left(>90^{\circ}\right)$, to ensure it is sufficiently hydrophobic to prevent wetting. To probe the pore structure of the commercial PTFE membranes, liquid-gas capillary flow porometry was performed. A representative pore size distribution is depicted in Fig. 3. As can be seen, the pore size distribution (PSD) is very narrow, with over $90 \%$ of the flow being measured through pores between 0.26 and $0.27 \mu \mathrm{m}$ in diameter. This is a favourable characteristic as there are no excessively small pores (which would increase mass transfer resistance) and no excessively large pores (which could allow for liquid intrusion). Whilst the mean pore size value is slightly higher than the $0.2 \mu \mathrm{m}$ reported by the manufacturer, it is still well suited to application in membrane distillation. 


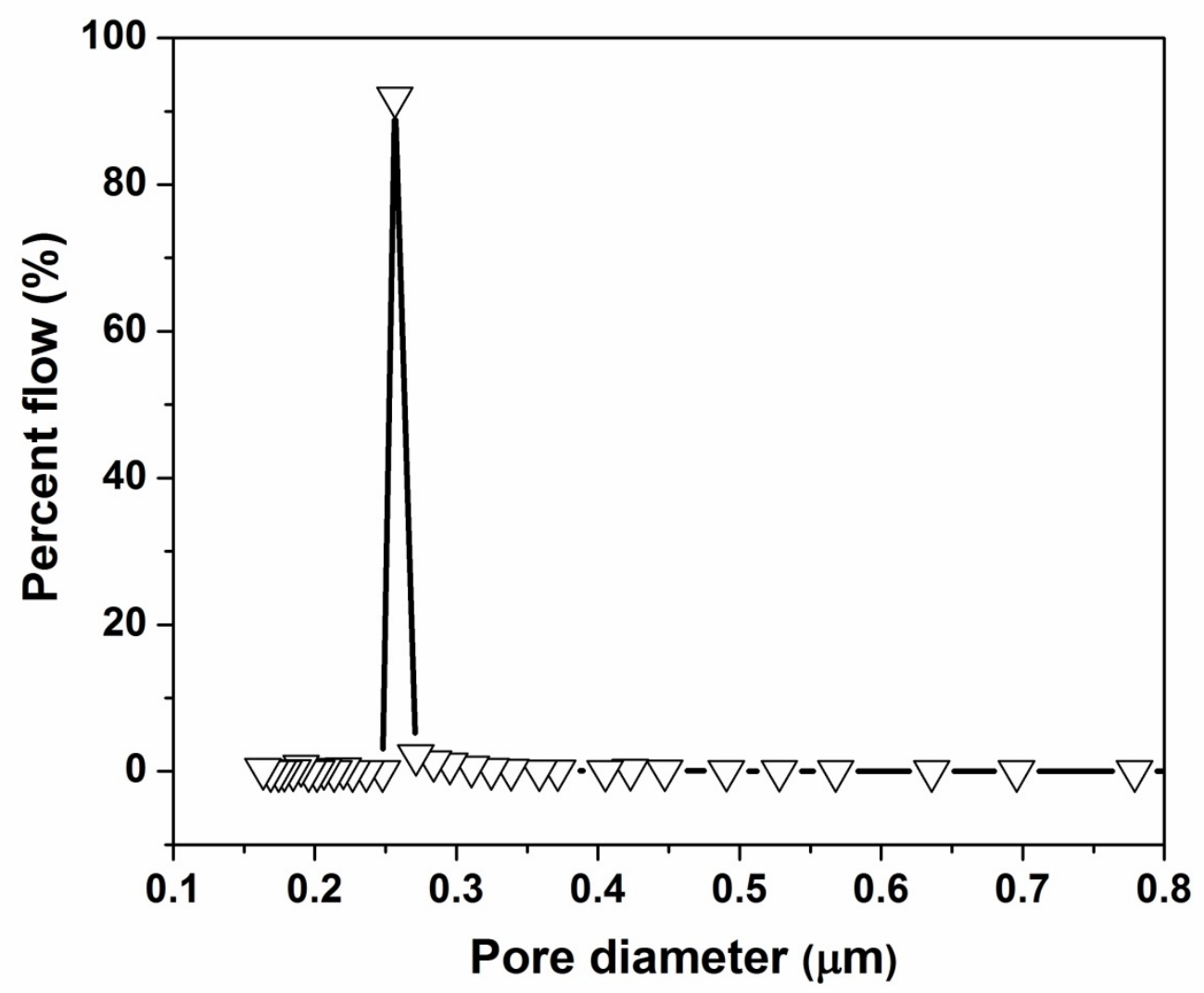

Fig. 3. A plot of percentage flow against pore diameter for the commercial PTFE membrane in which the peak value represents the mean pore size.

Other measured values for the membrane's properties are summarised in Table 1. The bubble point pore size (which is the first pore through which the gas can flow) was $0.395 \pm 0.091$ $\mu \mathrm{m}$, which is still a reasonable size to prevent wetting, given the membrane's fairly large contact angle of $105^{\circ}$. The membrane's porosity is a key property for determining flux in MD as it represents the free volume through which vapour transport can take place. A balance must be struck between high porosity and sufficient mechanical strength and in this case, the reported value of $80 \%$ is suitably high for this application. Due to a lack of available data on the polypropylene backing layer, it was not possible to verify the active layer porosity value experimentally. Finally, the measured thickness values are suitable for MD applications and are in close agreement with those reported by the manufacturer. 
Table 1. Reported and measured properties of the commercial PTFE membrane used in this study.

\begin{tabular}{|c|c|c|c|}
\hline Property & Reported value & Measured value & *Due to the \\
\hline Thickness $(\mu \mathrm{m})$ & 180 & $189.8( \pm 14.5)$ & 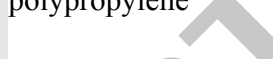 \\
\hline Porosity (\%) & 80 & -* & ssible \\
\hline Mean pore size $(\mu \mathrm{m})$ & 0.20 & $0.259( \pm 0.005)$ & accurately measure \\
\hline Bubble point pore size $(\mu \mathrm{m})$ & - & $0.395( \pm 0.091)$ & the porosity using \\
\hline Contact angle $\left({ }^{\circ}\right)$ & - & $105( \pm 3)$ & gravimetric \\
\hline
\end{tabular}

\subsection{AGMD performance}

The MD testing was performed using both discontinuous and continuous operation with the former totalling $20 \mathrm{~h}$ (with between 13 and $19 \mathrm{~h}$ of no operation or cleaning in between tests) and the latter totalling $70 \mathrm{~h}$ (for the solution containing all three components: $\mathrm{RB}, \mathrm{NaCl}$ and SDS). Fig. 4 shows the flux performance during the discontinuous filtrations using four different types of aqueous feeds including pure DI water, a solution containing $5 \mathrm{~g}$ of $\mathrm{NaCl}$ and $100 \mathrm{mg} \mathrm{RB}$ per litre, a solution $5 \mathrm{~g} \mathrm{NaCl}$ and $100 \mathrm{mg} \mathrm{SY}$ per litre and a solution containing $5 \mathrm{~g} \mathrm{NaCl}$ and both $\mathrm{RB}(100 \mathrm{mg})$ and surfactant SDS $(1 \mathrm{~g})$ per litre. The filtrations were paused at hours 6 and 17 as indicated in Fig. 4. As can be seen, the DI water flux $(J)$ was very constant throughout the experiment $\left(\sim 12.4 \mathrm{~L} \mathrm{~m}^{-2} \mathrm{~h}^{-1}\right.$, (LMH)), with intermittent periods of no operation, having observed no effect on the membrane performance. Furthermore, repeat testing with different membrane samples showed variations in the flux values of less than $3 \%$, indicating good uniformity in the membrane material.

Similarly, the flux pattern for the $\mathrm{SY}+\mathrm{NaCl}$ solution is relatively constant across the $20 \mathrm{~h}$. The flux $(J)$ started at a value of 12.4 LMH, there was a slight decline observed over the first few hours, reaching a minimum value of $11.6 \mathrm{LMH}(\sim 6.5 \%$ reduction $)$ by the sixth hour. However, upon continuing the experiment, the flux increased again back to its original value at hour 11 and then reached a maximum of $12.6 \mathrm{LMH}$ for hours 12 and 13 . The flux then 
slightly declined again, and at the end of the filtration after $20 \mathrm{~h}$ with a value of $12.0 \mathrm{LMH}$. For this solution, the flux varied across the whole experiment by a maximum of $7.9 \%$. The difference between the flux after $1 \mathrm{~h}$ and the flux after $20 \mathrm{~h}$ is only $-0.2 \mathrm{LMH}$. This flux stability is an indication that the membrane has not suffered from significant fouling over this time period.

The $\mathrm{RB}+\mathrm{NaCl}$ solution showed more evidence of flux decline at the beginning of the experiment but then plateaued from $15-20 \mathrm{~h}$. The initial flux was the highest of all tested solutions at $13.8 \mathrm{LMH}$ which began to steadily decline after $4 \mathrm{~h}$ to reach a minimum value of 12.3 LMH (a reduction of 10.9\%). The relative constancy of the flux from hour 12 to hour 20 suggests that the membrane performance had reached steady state and no significant fouling was taking place. Furthermore, even a reduction of $10.9 \%$ is considerably smaller than those reported in the literature for different configurations, as it will be discussed in section 3.5.

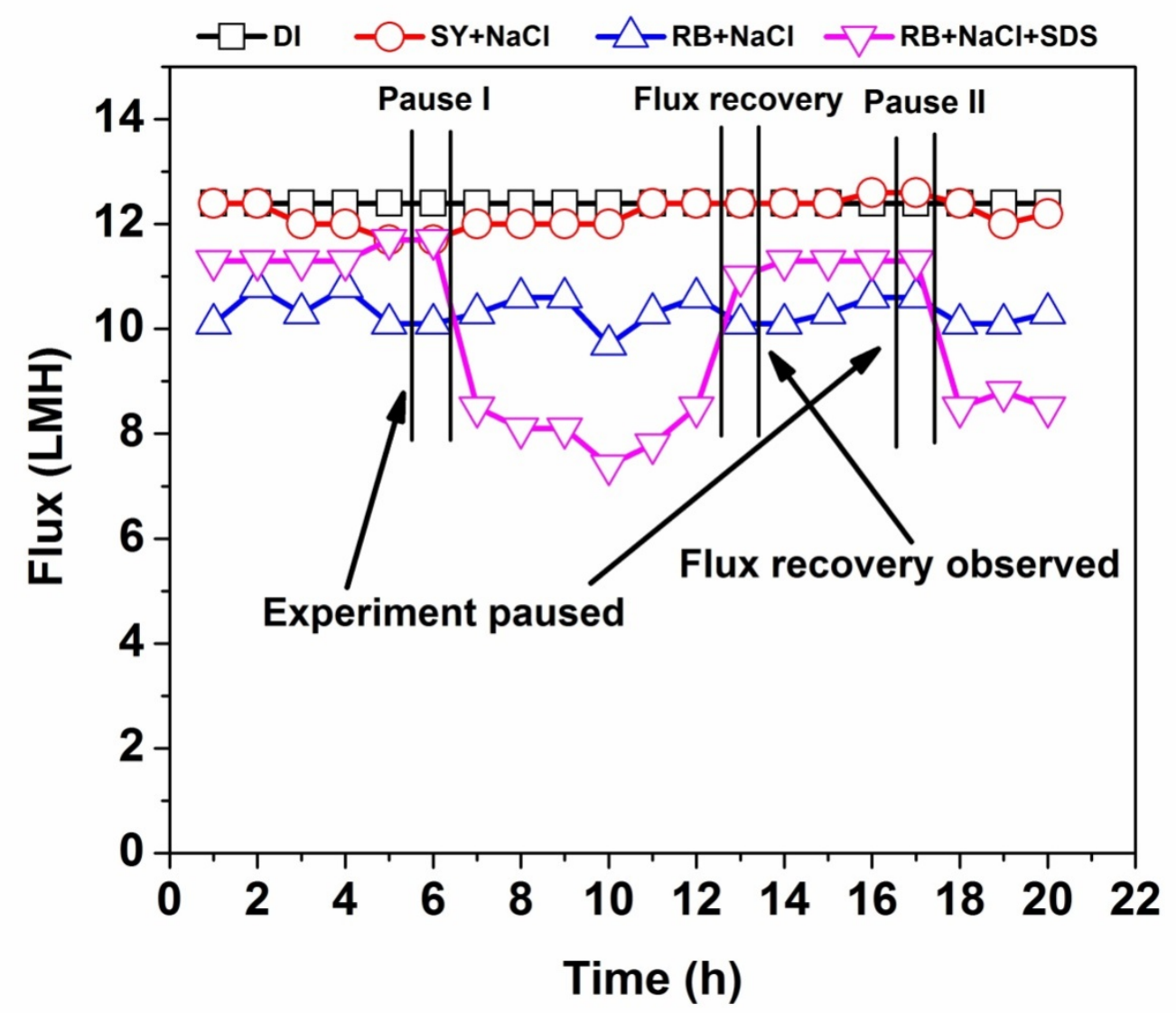


Fig. 4. Flux performance from discontinuous operation using DI water, binary mixtures (SY $+\mathrm{NaCl}$ and $\mathrm{RB}+\mathrm{NaCl})$ and the ternary mixture $(\mathrm{RB}+\mathrm{NaCl}+\mathrm{SDS})$ as feed solutions over $20 \mathrm{~h}$.

The most meaningful test to show that MD is appropriate for treating textile water however, is when the feed water contains surfactants. This is because their amphiphilic nature can cause them to adhere to the hydrophobic membrane and increase the chance of pore-wetting and flux decline. The flux performance for the test run when the feed solution was an aqueous solution containing $\mathrm{RB}, \mathrm{NaCl}$ and $\mathrm{SDS}$ was certainly evidence of the latter; the initial flux was steady at $11.3 \mathrm{LMH}$ for the first $4 \mathrm{~h}$ and then rose to $11.6 \mathrm{LMH}$ for hours 5 and 6 , at which point the operation was stopped overnight. After the test was initiated again, the flux had declined by $29.3 \%$ to be $8.2 \mathrm{LMH}$. This further declined slightly until a minimum value of $7.5 \mathrm{LMH}$ was reached. It is likely that the drying of the membrane overnight allowed for the SDS molecules to adhere to the membrane surface due to interactions with their hydrophobic tails, causing partial blocking of the pores and resulting in lower flux. However, after $10 \mathrm{~h}$ of testing, the flux began to increase. In fact, by hour 14 the flux had been restored to the same value as the beginning of the test (11.3 LMH). This flux recovery is an indication that this pore blockage was reversible and the flow of the feed water was sufficient to detach and re-dissolve the foulants in just a few hours, allowing $100 \%$ flux recovery. After $17 \mathrm{~h}$, the operation was again stopped overnight. Upon starting up the process again, the flux showed a similar degree of decline, presumably for the same reasons.

The permeate conductivity and the calculated SR values were very stable for the experiments run with feeds containing dye $+\mathrm{NaCl}$ as shown in Fig. 5. Very low conductivity values between 5 and $20 \mu \mathrm{S} \mathrm{cm} \mathrm{cm}^{-1}$ were obtained for the duration of the experiment. These corresponded to very high salt rejection values $(\sim 100 \%)$ as shown in Fig. 5 b. As well as high SR values, AGMD achieved perfect removal of dyes from the feed solutions and a very low total carbon content in the permeate of $0.37 \mathrm{ppm}$, as summarised in Table 2. This removal 
efficiency for each of the solute species demonstrates the potential of MD as a single-step water treatment solution and is further illustrated by Fig. 6 .

For the ternary feed solution, whilst the conductivity values were very low $\left(<30 \mu \mathrm{S} \mathrm{cm}^{-1}\right)$ for the first $17 \mathrm{~h}$, after $18 \mathrm{~h}$, this rapidly rose up to $305.3 \mu \mathrm{S} \mathrm{cm}^{-1}$ and continued rising up to a final value of $470 \mu \mathrm{S} \mathrm{cm}-1$ after $20 \mathrm{~h}$. A significant but less noticeable increase in the conductivity was also observed after $6 \mathrm{~h}$, when it rose from a base value of $2.8 \mu \mathrm{S} \mathrm{cm}^{-1}$ up to a value of $31.3 \mu \mathrm{S} \mathrm{cm}^{-1}$. Both step-wise increases in the permeate conductivity correspond to the times at which the experiment was paused (at hours 6 and 17). This is again attributed to the adhesion of SDS molecules to the membrane surface and was confirmed by water contact angle measurements; the water contact angle (WCA) dropped from a value of $105 \pm 3^{\circ}$ down to $93 \pm 8^{\circ}$ (see Table 3 ). As well as partially blocking the pores, this can reduce the hydrophobic character of the membrane due to the hydrophilic head of the molecule, increasing the chance of pore wetting thereby reducing the rejection. Between 8 and $17 \mathrm{~h}$, there was a slight reduction in the permeate conductivity which went from 21.2 to $13.4 \mu \mathrm{S}$ $\mathrm{cm}^{-1}$. This partial recovery of the rejection coincides with the observed recovery in flux and may be explained by the re-dissolution of the adhered species on the membrane surface during MD operation. The effect of the foulant layer on the permeate conductivity is discussed in more detail in section 3.4. 
a)

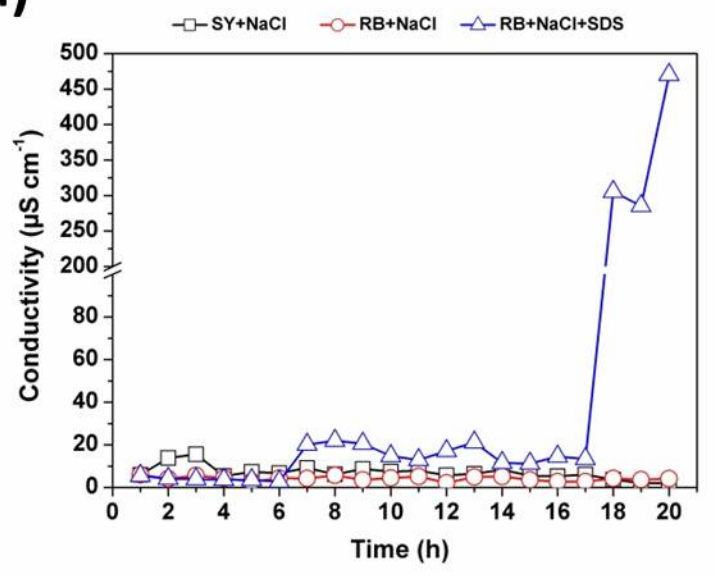

b)

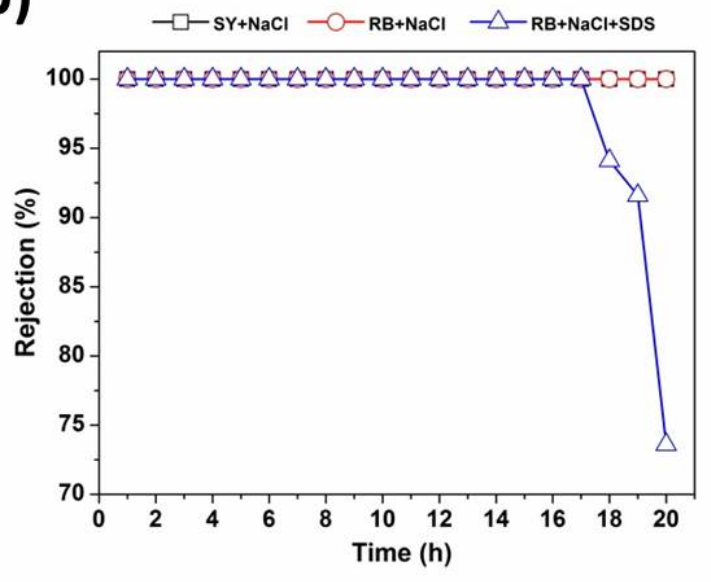

Fig. 5. a) Conductivity and b) solute rejection for AGMD tests run for $20 \mathrm{~h}$ with feed solutions containing $\mathrm{NaCl}$ and dyes $(\mathrm{SY}$ or $\mathrm{RB})$ and $\mathrm{NaCl}+\mathrm{RB}+\mathrm{SDS}$.

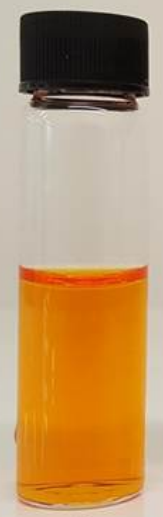

a)
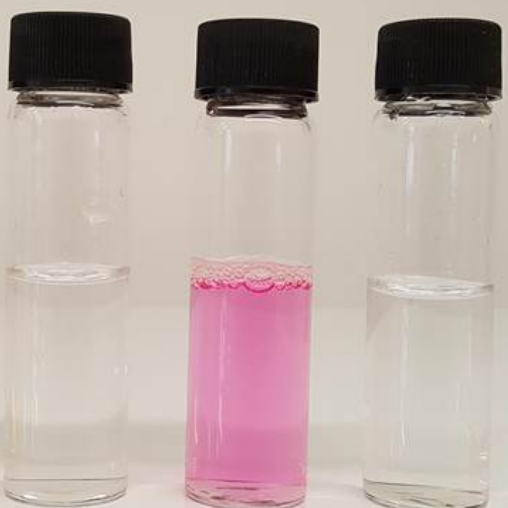

c)

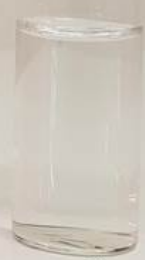

d)

Fig. 6. Optical image of the feed and permeate samples from AGMD, Here, a) and c) are respectively the binary sunset yellow dye $+\mathrm{NaCl}$ solution and the ternary rose Bengal dye + $\mathrm{NaCl}+\mathrm{SDS}$ surfactant solution. Images b) and d) are samples of the corresponding permeates from AGMD, which show the highly effective colour removal.

Table 2. Permeate flux, conductivity, dye rejection and total carbon from discontinuous AGMD testing.

\begin{tabular}{lllll} 
Feed solution & $\begin{array}{l}\mathbf{8} \text { h permeate flux } \\
(\mathbf{L M H})\end{array}$ & $\begin{array}{l}\text { Permeate Conductivity } \\
(\boldsymbol{\mu S} / \mathbf{c m})\end{array}$ & $\begin{array}{l}\text { Dye rejection } \\
(\%)\end{array}$ & $\begin{array}{l}\text { TC } \\
(\mathbf{p p m})\end{array}$ \\
\hline DI water & 12.4 & - & - & -
\end{tabular}




$\begin{array}{lcccc}\text { SY + salt } & 12.0 & 6.2 & 100 & - \\ \text { RB + salt } & 12.7 & 5.7 & 100 & 0.37^{*} \\ \text { RB }+ \text { salt + SDS } & 11.0 & 22.1 & 100 & 1.9 \\ \text { DCMD }^{* *} & 12.8 & 26.0 & 99.1 & \end{array}$

*TC was measured after $20 \mathrm{~h}$ AGMD operation.

** DCMD tests were performed using the ternary solution as the feed with a flow rate of $380 \pm 4 \mathrm{~mL} \mathrm{~min}^{-1}$.

Table 3. Water contact angle (WCA) for the tested PTFE membranes

\begin{tabular}{lcc} 
Membrane description & WCA $\left(^{\circ}\right)$ & From these results it \\
\hline Virgin PTFE & $105 \pm 3$ & $101 \pm 3$ \\
Tested with DI water for $6 \mathrm{~h}$ & $93 \pm 8$ & discontinuous \\
After $70 \mathrm{~h}$ of continuous testing with ternary mixture & operation, in which
\end{tabular}

the membrane is left immersed in the feed solution without flow, can contribute to porewetting and short-term flux reduction upon restarting the testing. It might therefore be recommended to perform continuous MD instead. In order to investigate this, longer term tests (up to $70 \mathrm{~h}$ ) were conducted in a continuous manner using the ternary feed solution. The results are shown in Fig. 7. Over the first $14 \mathrm{~h}$ of operation, the flux averaged 9.8 LMH whereas for the previous test in the discontinuous mode (Fig. 5) this was 11.3 LMH. However, flux reduction was observed for the continuous test, with it dropping down to 7.8 LMH after $15 \mathrm{~h}$. This is an indication that pore-blocking caused by the adhesion of SDS molecules was not prevented by continuous flow of the feed solution over the membrane. Nevertheless, between 15 and $20 \mathrm{~h}$ the flux began to rise dramatically, reaching a value of 11 LMH. At $24 \mathrm{~h}$ this value was still stable - far more so than reported values in the literature from other MD configurations (see Table 4). This observation was remarkably similar to the discontinuous operation in which significant flux recovery was observed without any intervention or cleaning of the membrane. One possible reason for this is that over time the fouling layer is likely to build up due to the amphiphilic structure of SDS giving rise to attractive forces between molecules. Eventually, the viscous drag forces of the feed solution 
become stronger than the interactions between the first layer of foulants and the membrane surface, effectively washing away that weakly-bound fouling layer and restoring the permeate flux back to initial values.

As shown in Fig. 7, the permeate conductivity values were initially very low $\left(22.72 \mu \mathrm{S} \mathrm{cm}^{-1}\right.$ after the first hour) and then rose somewhat between hour 15 and hour 40, reaching a value of $98.6 \mu \mathrm{S} \mathrm{cm}^{-1}$. As the testing progressed, the permeate conductivity increased more rapidly, indicating partial wetting of the membrane pores. This was accompanied by a more severe decline in the permeate flux. By the $70^{\text {th }}$ hour, the permeate conductivity had reached 421.8 $\mu \mathrm{S} \mathrm{cm} \mathrm{cm}^{-1}$ with a corresponding flux value of just under $3 \mathrm{LMH}$ (which may be a remedied by cleaning or back-flushing). Recall that in the discontinuous test (Fig. 4), the flux recovery was accompanied by a partial reduction in the permeate conductivity, indicating a reduction in the wetting of the membrane. However, in the continuous test this was not observed and the conductivity continued to rise throughout. This suggests there was incomplete removal of the adhered species from the membrane surface with some surfactant molecules still present and able to cause partial wetting. The flux recovery may have been due to a partial removal of a pore-blocking layer, which left behind some species attached to the pore entry points. Whilst the final conductivity value $\left(421.8 \mu \mathrm{S} \mathrm{cm}^{-1}\right)$ is considerably higher than the initial values, it is important to note that this is still well below the maximum allowed values for drinking water (2500 $\left.\mu \mathrm{S} \mathrm{cm}^{-1}\right)$ according to European regulations [37]. 


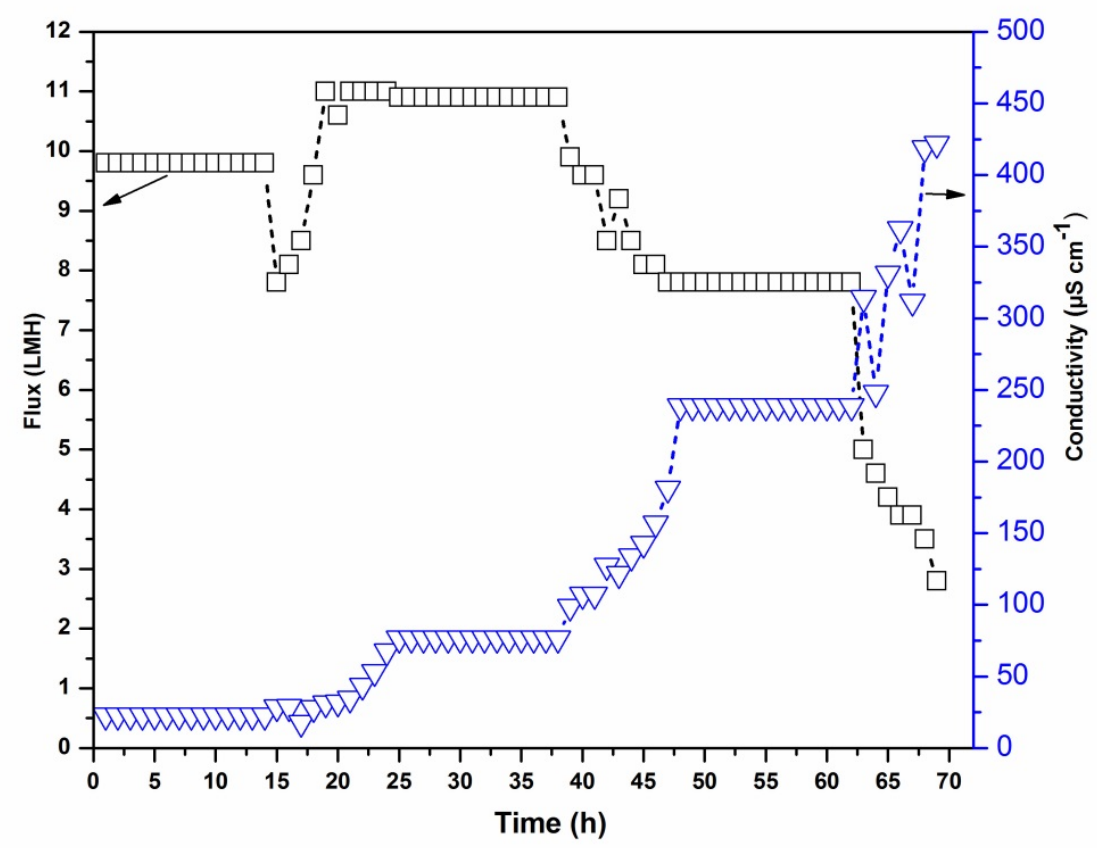

Fig. 7. Flux and permeate conductivity values over $70 \mathrm{~h}$ of continuous testing of the ternary feed solution containing $\mathrm{RB}+\mathrm{NaCl}+\mathrm{SDS}$.

The increase in permeate conductivity is consistent with the change in the water contact angle value as shown in Table 3. After the long term testing was conducted, WCA measurements were taken to see how the fouling of the membrane affected the wetting properties. As can be seen, there is little effect after testing with DI water, with the change from 105 to $101^{\circ}$ representing only a $\sim 4 \%$ reduction (and there is already $\sim 3 \%$ variation across measurements of the same membrane). However, after $70 \mathrm{~h}$ of testing with the ternary mixture, the mean contact angle value dropped by $13 \%$ to $93 \pm 8^{\circ}$. This is a further suggestion that the hydrophilic head of SDS is sticking out of the membrane surface as the hydrophobic tail is orientated towards the PTFE. The larger standard deviation in the measurement is also an indication that the fouling layer is not homogenous across the membrane, with some regions being particularly well covered and others where the PTFE was mostly exposed. This can be seen in the SEM images in Fig. 8. The lower WCA indicates that the membrane has become 
less hydrophobic, which in turn means the liquid entry pressure is reduced and so the likelihood of the feed liquid penetrating the pores and entering the permeate side is increased.

\subsection{Membrane fouling}

Since an MD membrane acts as a selective barrier between the vapour and liquid phases, rather than being size or charge-selective, it is necessary to avoid the phenomenon of pore wetting throughout its operation. The phenomenon occurs when the hydraulic pressure of the feed overcomes the liquid entry pressure of the largest pore in the membrane. This is more likely to happen when the feed water contains organic matter, which can lower its surface tension and deposit on the membrane as a foulant. In addition, the presence of inorganic salts in the feed water can cause scaling on the pore entrances, which can provide a passage for the liquid water to migrate through to the permeate side [38]. In this work, the salt used in the feed water was $\mathrm{NaCl}$ which is highly water soluble and so unlikely to crystallise and cause wetting at the concentrations used. Therefore, pore-wetting was most likely caused by adhesion of the surfactant (SDS) and dye (rose Bengal), to the membrane's hydrophobic surface.

To investigate this, SEM images were taken of the PTFE membrane before and after $70 \mathrm{~h}$ of continuous testing. As can be seen in Fig. 8, the fibril structure of the PTFE was just about visible in both cases. However, in the fouled membrane this fibril structure is mostly covered by a thick amorphous foulant layer. The higher magnification image (Fig. 8d) shows how this foulant layer has covered the voids between the fibrils, reducing the number open pores. One mechanism behind this is the hydrophobic interactions between the membrane surface and the tails of the SDS molecules which are less stable in the water phase. As they adhered to the membrane surface, the charged sodium ion at the head of the SDS molecule attracted water molecules. This effectively reduced the surface tension of the water on the membrane surface, causing pore wetting [25]. Furthermore, the blocking of the pores by these adhered 
SDS molecules contributed to the flux reduction observed in the MD experiments as well as the increase in permeate conductivity.

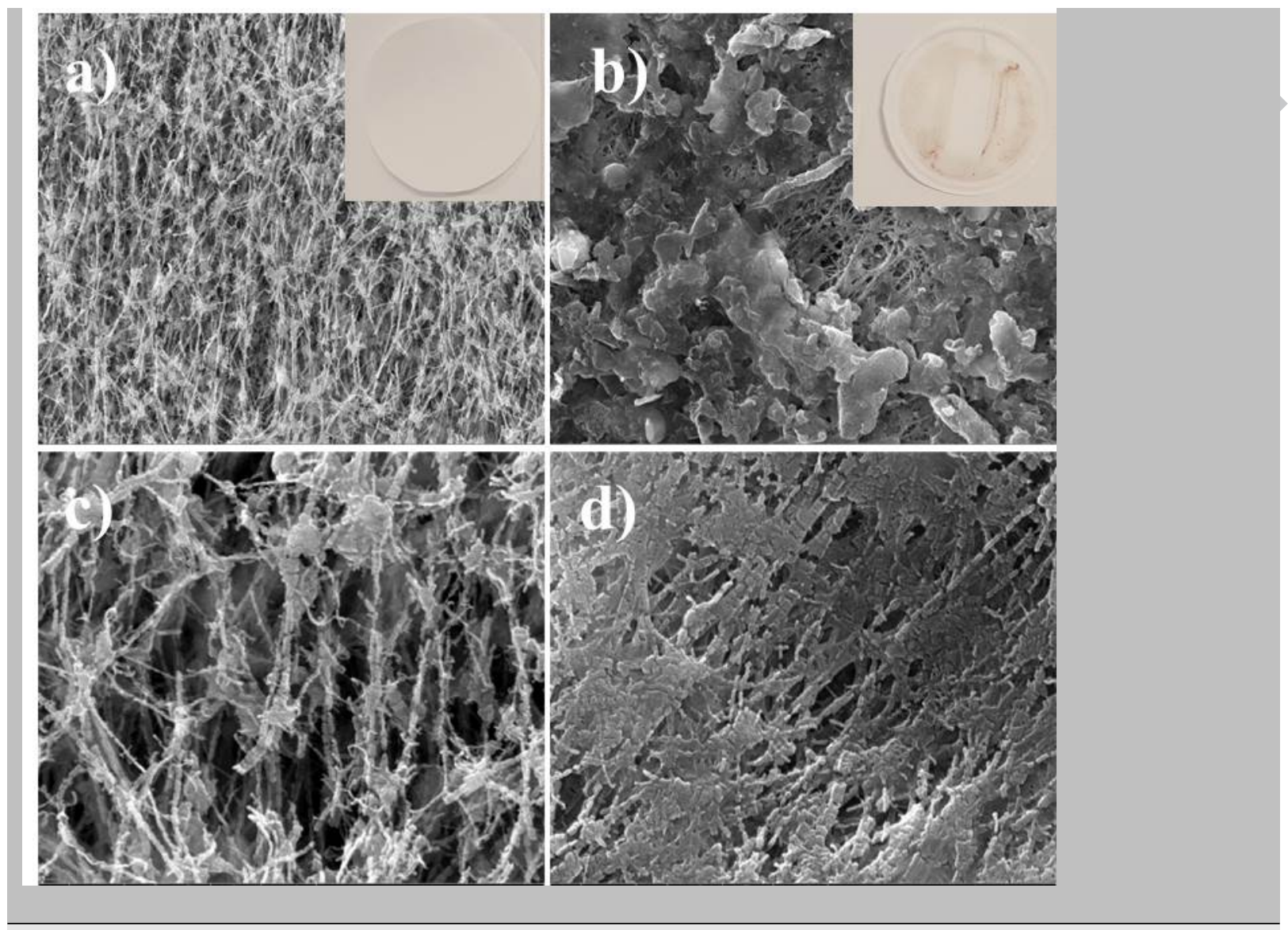

Fig. 8. Representative SEM images of the PTFE membranes before (a \& c) and after (b \& d)

$70 \mathrm{~h}$ of continuous testing with the ternary feed solution at different magnifications. Inset images in a) and b) are photographs of the membranes before (left) and after (right) testing. Scale bars represent $10 \mu \mathrm{m}$ for a) $\&$ b) and $3 \mu \mathrm{m}$ for c) $\&$ d).

To investigate the chemistry of the foulant later, the membranes were analysed using ATRFTIR, as shown in Fig. 9. The FTIR spectra of the clean PTFE membrane show typical transmittance bands at $1204 \mathrm{~cm}^{-1}$ and $1147 \mathrm{~cm}^{-1}$ assigned to the stretching mode of the C-F bonds. For the fouled PTFE membrane however, more peaks are observed at $2964 \mathrm{~cm}^{-1}$, $2915 \mathrm{~cm}^{-1}, 2285 \mathrm{~cm}^{-1}, 1727 \mathrm{~cm}^{-1} 1498 \mathrm{~cm}^{-1}, 1465 \mathrm{~cm}^{-1}$ and $1095 \mathrm{~cm}^{-1}$. According to the FTIR standard spectra, the bands at $2850-2964 \mathrm{~cm}^{-1}$ are assigned to the $\mathrm{C}-\mathrm{H}$ stretching mode from the SDS chain, whereas the peak at $1727 \mathrm{~cm}^{-1}$ is attributed to the stretching mode of $\mathrm{C}=$ C alkane bonds of the rose Bengal dye (Fig. 1) [39]. The band at $1095 \mathrm{~cm}^{-1}$ is assigned to the 
$\mathrm{C}-\mathrm{O}-\mathrm{C}$ stretching mode of alicyclic ether. The intensities of PTFE characteristic peaks are noticeably reduced after fouling due to the covering by foulants. Meanwhile, the higher concentration of the carbon and oxygen functionalities in the fouled membrane can be attributed to the presence of SDS and rose Bengal dye which adhered to the membrane surface over the duration of the experiments.

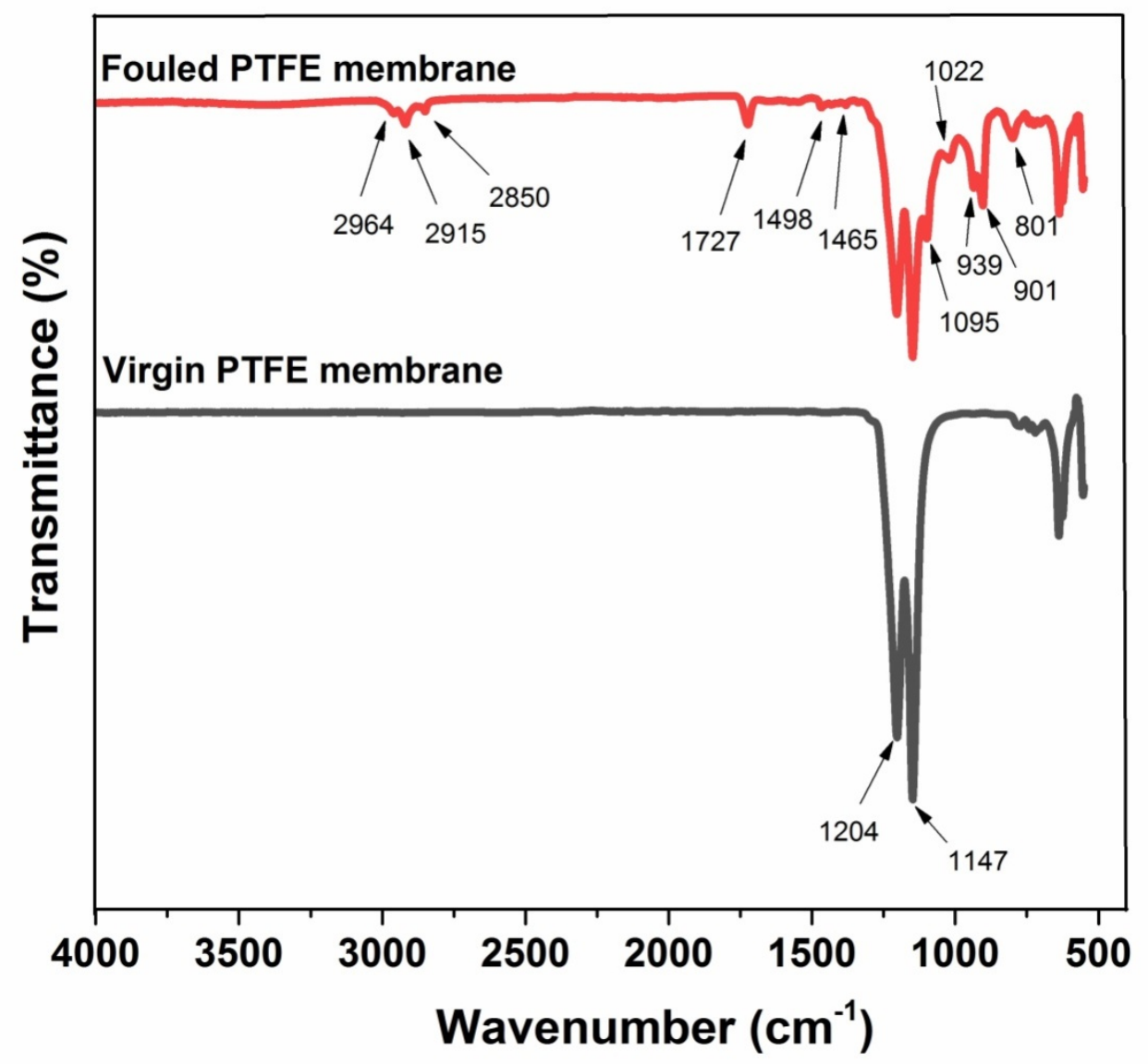

Fig. 9. FTIR spectra of (a) virgin PTFE, and (b) fouled PTFE membranes.

\subsection{AGMD vs DCMD}

In order to compare the performance of the air gap configuration with the more commonly tested direct contact configuration, 8 hour DCMD tests were performed using the ternary feed solution with the same feed and permeate side temperatures of 70 and $20{ }^{\circ} \mathrm{C}$, respectively. The flux and separation performances are presented in Table 2 and Fig. 10. After $8 \mathrm{~h}$ of testing with the ternary feed solution, the DCMD flux was slightly higher than that of AGMD with a value of 12.8 LMH compared to 11.0 LMH. It is expected that the flux 
is higher in DCMD than AGMD due to the reduced mass transfer resistance given the absence of the air layer. However, the observed difference of $16.3 \%$ was quite modest. The DCMD flux was lower than is common in the literature, although reported values vary considerably [40-42]. However, higher feed flow rates resulted in higher fluxes, as described shortly. Another potential reason for lower DCMD flux could be due to the membrane's PP non-woven backing. This layer has a very open, fibrous structure which may trap some of the permeate inside it, reducing the extent to which it can circulate through the module and thereby increasing the temperature polarisation. This would not affect the flux in AGMD because there is little to no permeate condensation taking place inside the membrane.

Despite the slightly lower flux, the separation performance of AGMD was found to be better than DCMD in terms of permeate conductivity, colour removal and carbon content rejection. In all AGMD tests, the colour removal was $100 \%$ whereas this dropped to $99.1 \%$ for DCMD tests over just 8 hours. The permeate conductivity and total carbon content were also higher for DCMD. To see if this reduction in separation performance was related to the feed flow rate, $\mathrm{Q}_{\mathrm{f}}$, three tests were performed, using $\mathrm{Q}_{\mathrm{f}}=226,380$ and $1020 \mathrm{~mL} \mathrm{~min}{ }^{-1}$. This revealed that at higher flow rates, the DCMD flux increased and the permeate conductivity (generally) decreased. Both of these observations were expected, the former being due to improved heat transfer and reduced temperature polarisation [43] and the latter being due to greater shear forces overcoming the interactions between the foulant molecules and the membrane surface [18]. Nevertheless, over the 8 hours of testing, the flux declined by $\sim 6 \%$ and $\sim 15 \%$ for the highest and lowest flow rates, respectively and the permeate conductivity values at all flow rates were still higher than for AGMD. This is due to the fact that in DCMD there is a high chance of permeate-side wetting occurring if species on the feed side manage to permeate through the membrane. In AGMD, even if this happens, there is no liquid directly in contact with the permeate side of the membrane and so the foulant species are less 
able to enter the permeate. This is an advantage that AGMD has over DCMD and whilst in both cases, membrane cleaning will still eventually be required to maintain flux values, the risk of permeate contamination during operation is, in principle, lower in AGMD [44]. These findings further support the idea of utilizing AGMD over DCMD as an effective single step treatment process for representative textile wastewater.

a)

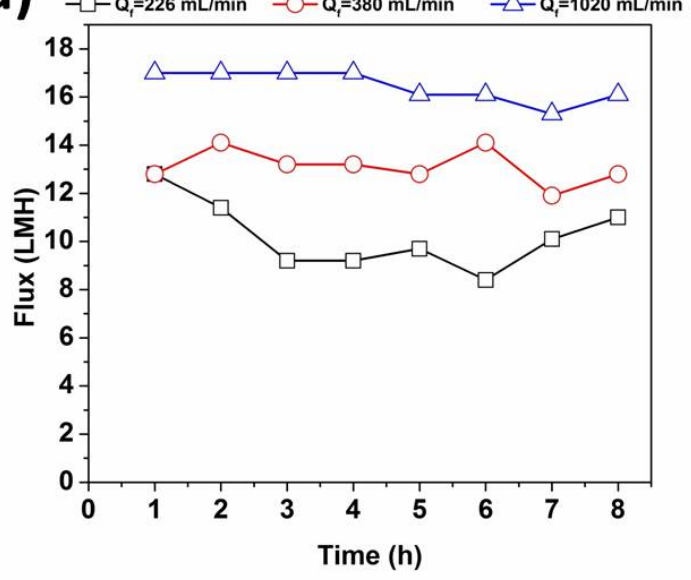

b)

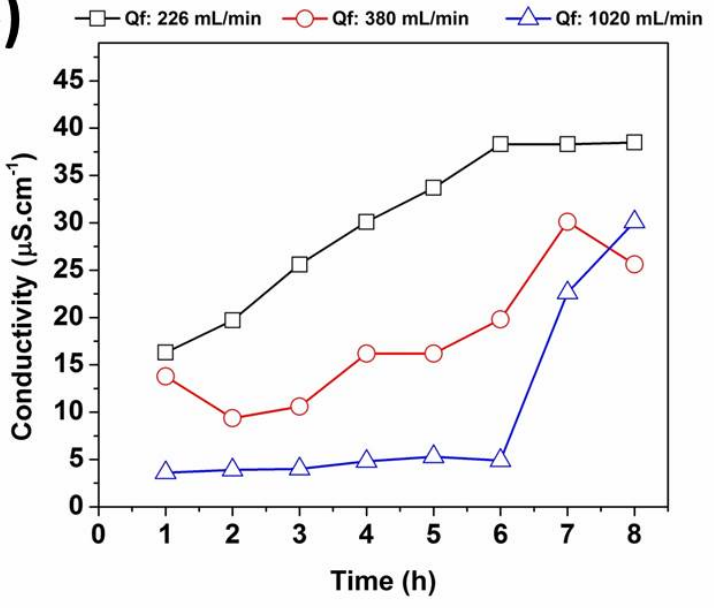

Fig. 10 Flux (a) and conductivity (b) values for the 8 hour DCMD tests with the ternary feed solution at three different feed flow rates, Qf. The feed and permeate temperatures were 70 and $20 \mathrm{oC}$, respectively and the permeate flow rate was kept at $300 \mathrm{~mL} \mathrm{~min}^{-1}$.

\subsection{Energy consumption and outlook}

As well membrane distillation's ability to effectively treat a wide range of water types, its ability to be driven by energy from waste heat sources makes it potentially attractive for industries which produce a lot of waste heat in their operations, such as the textile industry. However, it is important to consider the relationship between the specific thermal energy consumption (STEC) of an MD system and the quantity of waste heat available from the industry in question. For this discussion we refer to examples in the literature as it is well known that a single stage MD module (as used in these experiments) is not optimised for thermal efficiency or heat recovery. To indicate the best case scenario, we refer to the Memstill ${ }^{\circledR}$ process, which was mentioned in the introduction and has the lowest reported 
STEC values that we could identify from the literature. This system is based on AGMD and has internal heat recovery built into the module geometry. The STEC value for this process (for treating seawater) is $72 \mathrm{kWh} \mathrm{m}^{-3}[30]$.

There are a variety of potential sources of waste heat in a typical textile plant. Rakib et al. [45] identified 6 main sources: generator exhausts, boiler exhausts, dyeing wastewater, steam condensate, stenter exhaust and blowdown water. Of these, the largest source of waste heat was in the dyeing wastewater, with $29.0 \%$ of the energy used in the dyeing process being lost. In this particular plant, which was releasing up to $1200 \mathrm{~m}^{3}$ of hot wastewater every day, the quantity of lost energy was 34,035 MWh. Using a STEC value for an MD system of 72 $\mathrm{kWh} \mathrm{m}^{-3}$, this could produce $473 \mathrm{~m}^{3}$ of pure distillate. This represents a recovery value of $39 \%$. Therefore, even in the ideal case, MD would not be able to treat $\sim 60 \%$ of the wastewater produced using only the heat embedded in the dyeing water. In reality, this value would be much lower due to system inefficiencies. For example, in this case study, of the total amount of lost energy in the process only $5716 \mathrm{MWh}$ was successfully recovered using heat exchangers. This would reduce the potential MD distillate production to $6.6 \%$ of the total wastewater produced. This may be increased if the other sources of waste heat were harnessed as well, or if additional heat sources such as solar thermal panels were employed but this would likely increase the complexity and cost of the process.

Another study tested a pilot DCMD system to treat textile wastewater by utilising the $1 \mathrm{MW}$ waste heat potential of a $6 \mathrm{MW}$ boiler. In this case the plant was producing $1000 \mathrm{~m}^{3} / \mathrm{day}$ of wastewater of which $96 \mathrm{~m}^{3}(0.96 \%)$ could be treated assuming a low STEC of $150-250$ $\mathrm{kWh} \mathrm{m}^{-3}$. However, the authors noted that if this waste volume was reduced by conventional treatment processes, such as RO, it would be possible to use MD to concentrate the brine further using the available waste heat [4]. Interestingly, this work also described the presence of ammonia in the permeate stream which originated from the wastewater. Other research has 
shown how membrane distillation can be used to recover ammonia from agricultural waste as an attempt to reuse valuable resources $[46,47]$. This additional use for membrane distillation, if properly developed, could provide additional value to the textile industry which could favourably alter the economics of the process. For further discussion about this use of MD, the readers are referred to the literature [48-52]. Whilst AGMD is able to treat complex wastewater in one step, the thermal energy demand is currently too high for it to treat all of the wastewater produced. Efforts should therefore be made to reduce the energy demand of MD and identify other economically favourable strategies, such as resource recovery textile to bridge this gap.

\subsection{Comparison with the literature}

The use of MD technology for treating wastewater has been reported in a modest but increasing number of publications as reported in a recent review [24]. Permeate fluxes in this work lie mostly in the range of 9-12 LMH, which is slightly lower than other AGMD studies using PTFE membranes [53-55]. This is attributed to lower flow rates used here as well as our use of the total membrane area (rather than effective membrane area) to calculate flux, as described in the experimental section. Table 4 summarises the data from a selection papers in the literature representing the wide range of feed water types, membrane materials and operating conditions tested. As shown in Table 4, DCMD is the most common MD configuration used for treating dyeing wastewater. For instance, An et al. [56] utilized two hydrophobic membranes (PVDF and PTFE) in treating feeds containing different kinds of dyes (i.e. acidic, basic, azo-dye and neutral) using the DCMD configuration. They reported between 13 and $21 \%$ flux reduction over $24 \mathrm{~h}$ of testing, depending on the feed and achieved $100 \%$ colour removal in all cases. Moktar et al. [57] observed consistent permeate flux averaging 9.82 LMH with 99.86\% rejection of reactive black dye using PVDF membranes blended with ethylene glycol in DCMD. Together with our results from the AGMD tests 
using the binary feed solution (Fig. 5), this shows how capable MD is at treating simple dye solutions, although treating more complex mixtures is the real test for MD in this application. In this vein, Molehtar et al. [58] used PVDF-Cloisite 15A nanocomposite membranes in DCMD to treat real textile wastewater without any pre-treatment and found that the flux reduced rapidly over the first $10 \mathrm{~h}$ by approximately $50 \%$. However, after this the flux continued to decline but much more gradually, eventually reducing by $56 \%$ after $40 \mathrm{~h}$ operation compared to an initial value of $38 \mathrm{LMH}$. Despite the observed flux decline, the fact that the water had no pre-treatment is a good indication that membrane distillation has potential a single step process for this application. Also using DCMD for the treatment of real textile wastewater, Garcia et al. [59] employed a novel hydrophilic coating on PTFE membranes to try and reduce membrane fouling whilst treating textile wastewater. The aim was to reduce the adhesion of surfactant molecules which could cause wetting of the membrane whilst retaining the anti-wetting property of the hydrophobic PTFE layer beneath. Whilst the unspecified hydrophilic coating partially mitigated the rise in the permeate electrical conductivity (observed for the pure PTFE membrane), this property was lost after a caustic cleaning step. The authors noted the potential of MD to this application but suggested that cleaning protocols needed further development.

VMD has also been used to treat single-component dye solutions using polypropylene-based membranes. Whilst the dye rejection was $100 \%$ in each case, flux reductions of between 18 and $26 \%$ occurred after only $1.75 \mathrm{~h}$ of testing [26]. A more severe flux reduction was described in another VMD experiment [27] which showed an exponential decrease in the flux over the first 40 minutes from 30.3 to $1.2 \mathrm{LMH}$. The applied vacuum pressure resulted in significant pore blocking by the methylene blue dye used in the feed stream, although the flux stabilised between 40 and 100 minutes of testing at around 1.3 LMH. It seems from our observations that AGMD is a more suitable configuration in terms of flux stability than 
VMD, especially given that the abovementioned VMD tests only tested single-component dye solutions. Furthermore, since AGMD has higher thermal efficiency than DCMD due to reduced sensible heat loss through the membrane, it may well be better suited to textile wastewater treatment which has appreciable but finite thermal energy available (from the dyeing process itself). Since the aim of any water treatment technology is to successfully treat the water whilst ensuring minimal environmental impact, consideration for the source of energy which drives the process is crucial. More work is needed to develop effective cleaning protocols or identify simple pre-treatment steps if this technology is to be implemented commercially. Nevertheless, the prospect of MD being able to reduce what is currently a highly complex, multistage water treatment procedure into just one or two steps is highly motivating.

It is also worth mentioning that recent research work on the development of superhydrophobic and omniphobic MD membranes has been shown an effective way to overcome the limitations of commercial PTFE membranes in terms of fouling and long term performance of MD $[60,61]$.

Table 4. Literature survey of flux, flux decline and rejection performance

\begin{tabular}{|c|c|c|c|c|}
\hline Config. & $\begin{array}{c}\text { Membrane } \\
\text { material }\end{array}$ & Operating parameters & $\begin{array}{l}\text { Colour } \\
\text { removal (\%) }\end{array}$ & Water type \\
\hline DCMD & $\begin{array}{l}\text { PVDF-0.22 } \\
\mu \mathrm{m}\end{array}$ & $\begin{array}{l}\text { Operation time: } 24 \mathrm{~h} \\
\text { Feed / coolant } \\
\text { Temp: } 60^{\circ} \mathrm{C} / 20^{\circ} \mathrm{C} \\
\text { Flow rate: } 0.5 \mathrm{~L} \mathrm{~min}^{-1} / 0.5 \mathrm{~L} \mathrm{~min}^{-1}\end{array}$ & $\begin{array}{l}100 \text { (in all } \\
\text { cases) }\end{array}$ & $\begin{array}{l}\text { MB } \\
\text { CV } \\
\text { AR } 18 \\
\text { AY } 36\end{array}$ \\
\hline DCMD & $\begin{array}{l}\text { PVDF-0.45 } \\
\mu \mathrm{m}\end{array}$ & $\begin{array}{l}\text { Operation time: } 24 \mathrm{~h} \\
\text { Feed / coolant } \\
\text { Temp: } 60^{\circ} \mathrm{C} / 20^{\circ} \mathrm{C} \\
\text { Flow rate: } 0.5 \mathrm{~L} \mathrm{~min}^{-1} / 0.5 \mathrm{~L} \mathrm{~min}^{-1}\end{array}$ & $\begin{array}{l}100 \text { (in all } \\
\text { cases) }\end{array}$ & $\begin{array}{l}\text { MB } \\
\text { CV } \\
\text { AR } 18 \\
\text { AY } 36\end{array}$ \\
\hline DCMD & PTFE & $\begin{array}{l}\text { Operation time: } 24 \mathrm{~h} \\
\text { Feed / coolant } \\
\text { Temp: } 60^{\circ} \mathrm{C} / 20^{\circ} \mathrm{C} \\
\text { Flow rate: } 0.5 \mathrm{~L} \mathrm{~min} \text { mi }^{-1} 0.5 \mathrm{~L} \mathrm{~min}^{-1}\end{array}$ & $\begin{array}{l}100 \text { (in all } \\
\text { cases) }\end{array}$ & $\begin{array}{l}\text { MB } \\
\text { CV } \\
\text { AR } 18 \\
\text { AY } 36\end{array}$ \\
\hline DCMD & $\begin{array}{l}\text { PVDF- } \\
\text { Cloisite } \\
15 \mathrm{~A}\end{array}$ & $\begin{array}{l}\text { Operation time: } 40 \mathrm{~h} \\
\text { Feed / coolant } \\
\text { Temp: } 90^{\circ} \mathrm{C} / 25^{\circ} \mathrm{C} \\
\text { Flow rate: } 0.023 \mathrm{~m} \mathrm{~s}^{-1} / 0.002 \mathrm{~m} \mathrm{~s}^{-1}\end{array}$ & $\begin{array}{l}95.3(150 \\
\min )\end{array}$ & $\begin{array}{l}\text { Textile } \\
\text { wastewater }\end{array}$ \\
\hline DCMD & PTFE-0.22 & Operation time: $190 \mathrm{~h}$ & NA & Textile \\
\hline
\end{tabular}




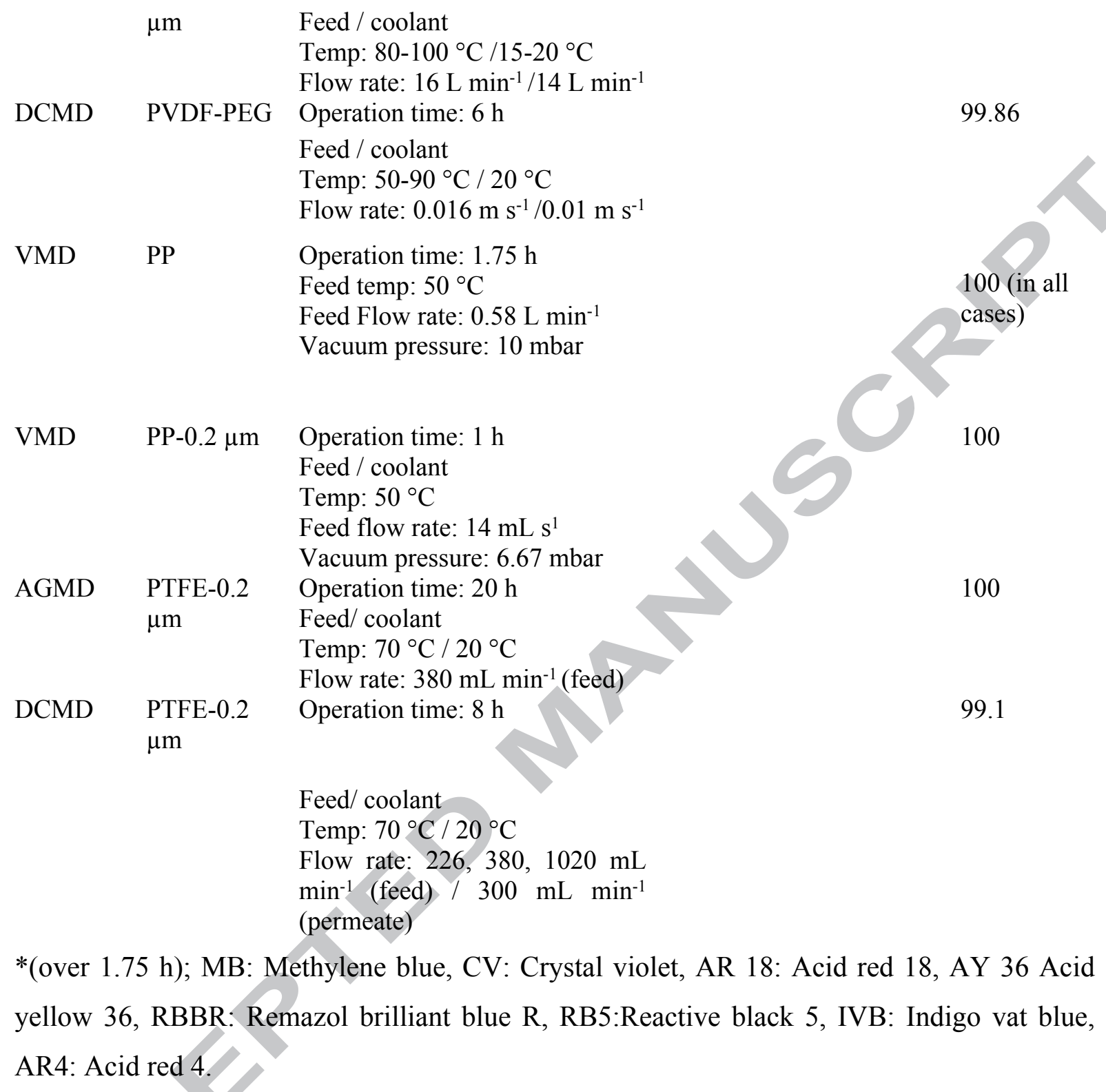

\section{Conclusion}

This work demonstrates the feasibility of using air gap membrane distillation to treat complex simulated dye wastewater containing three of the main dissolved species present in real wastewater, namely salts, dyes and surfactants. Long term (20 h) AGMD tests achieved complete rejection of dyes, SDS surfactant and $\mathrm{NaCl}$ using a commercial PTFE membrane with a reasonably high permeate flux of 9.6 $\mathrm{LMH}$ at the end of the test. Temporary stoppages in this testing showed corresponding reductions in the flux values. However, $100 \%$ flux recovery was observed after a few hours of beginning the testing again as the flow of water 
effectively 'cleaned' the membrane. Surprisingly, this same phenomenon was observed for continuous operation. After prolonged and continuous operation for $70 \mathrm{~h}$, dye rejection was maintained at a $100 \%$ whereas the salt rejection decreased down to $91 \%$, indicating partial wetting due to membrane fouling by SDS and rose Bengal dye. This corresponded to more severe flux decline to a final value of $\sim 3 \mathrm{LMH}$, which suitable cleaning protocols need to be developed and implemented in order to mitigate. DCMD tests resulted in reduced rejection performance and only slightly higher fluxes. This was attributed to the possibility or permeate side wetting allow for any foulants that have entered the pores to be carried into the permeate whereas this was not possible in AGMD due to the condensation occurring away from the membrane surface. The simplicity of AGMD and its potential to be integrated with the heat sources already available in textile dyeing processes make it an attractive water treatment method for this application, although reductions in the STEC on full scale processes is needed in order to achieve high water recycling rates using waste heat alone. Future membrane development may help to reduce fouling and improve the long term performance of MD for this kind of wastewater or perhaps a simple pre-treatment step can be a more effective strategy. The challenge of treating complex and potentially harmful textile wastewater must be met if this global industry is to become sustainable and environmentally responsible in the future.

\section{Acknowledgements}

Sebastian Leaper would like to acknowledge EPSRC for funding the NOWNANO CDT. Ahmed Abdel-Karim would like to acknowledge the Ministry of Higher Education (MoHE) of Egypt and the Newton-Mosharaffa Fund.

\section{References}


[1] A.M. El-Dein, J. Libra, U. Wiesmann, Cost analysis for the degradation of highly concentrated textile dye wastewater with chemical oxidation $\mathrm{H} 2 \mathrm{O} 2 / \mathrm{UV}$ and biological treatment, J. Chem. Technol. Biotechnol., 81 (2006) 1239-1245.

[2] C. Sahunin, J. Kaewboran, M. Hunsom, Treatment of textile dyeing wastewater by photo oxidation using UV/H2O2/Fe2+ reagents, ScienceAsia, 32 (2006) 181-186.

[3] WTO, World Trade Statistical Review, in, 2017, pp. 34.

[4] N. Dow, J.V. García, L. Niadoo, N. Milne, J. Zhang, S. Gray, M. Duke, Demonstration of membrane distillation on textile waste water: assessment of long term performance, membrane cleaning and waste heat integration, Environ. Sci. Water Res. Technol., 3 (2017) 433-449.

[5] A. Ghaly, R. Ananthashankar, M. Alhattab, V. Ramakrishnan, Production, characterization and treatment of textile effluents: a critical review, J. Chem. Eng. Process Technol., 5 (2014) 1-18.

[6] I.-I. Savin, R. Butnaru, Wastewater characteristics in textile finishing mills, Environ. Eng. Manage. J., 7 (2008).

[7] F.P. Van der Zee, S. Villaverde, Combined anaerobic-aerobic treatment of azo dyes-a short review of bioreactor studies, Water Res., 39 (2005) 1425-1440.

[8] F.M.D. Chequer, G.A.R. de Oliveira, E.R.A. Ferraz, J.C. Cardoso, M.V.B. Zanoni, D.P. de Oliveira, Textile Dyes: Dyeing Process and Environmental Impact, 2013.

[9] A.K. Verma, R.R. Dash, P. Bhunia, A review on chemical coagulation/flocculation technologies for removal of colour from textile wastewaters, J. Environ. Manage., 93 (2012) 154-168.

[10] I. Vergili, Y. Kaya, U. Sen, Z.B. Gönder, C. Aydiner, Techno-economic analysis of textile dye bath wastewater treatment by integrated membrane processes under the zero liquid discharge approach, Resour. Conserv. Recycl., 58 (2012) 25-35. 
[11] K. Ranganathan, K. Karunagaran, D. Sharma, Recycling of wastewaters of textile dyeing industries using advanced treatment technology and cost analysis-case studies, Resour. Conserv. Recycl., 50 (2007) 306-318.

[12] A. Hasanbeigi, L. Price, A technical review of emerging technologies for energy and water efficiency and pollution reduction in the textile industry, J. Cleaner Prod., 95 (2015) $30-44$.

[13] S. Shirazi, C.J. Lin, D. Chen, Inorganic fouling of pressure-driven membrane processes A critical review, Desalination, 250 (2010) 236-248.

[14] J.H. Teng, L.G. Shen, G.Y. Yu, F.Y. Wang, F.Q. Li, X.L. Zhou, Y.M. He, H.J. Lin, Mechanism analyses of high specific filtration resistance of gel and roles of gel elasticity related with membrane fouling in a membrane bioreactor, Bioresource Technology, 257 (2018) 39-46.

[15] J.R. Chen, M.J. Zhang, F.Q. Li, L. Qian, H.J. Lin, L.N. Yang, X.L. Wu, X.L. Zhou, Y.M. He, B.Q. Liao, Membrane fouling in a membrane bioreactor: High filtration resistance of gel layer and its underlying mechanism, Water Res., 102 (2016) 82-89.

[16] A. Alkhudhiri, N. Darwish, N. Hilal, Membrane distillation: a comprehensive review, Desalination, 287 (2012) 2-18.

[17] A.M. Alklaibi, N. Lior, Membrane-distillation desalination: status and potential, Desalination, 171 (2005) 111-131.

[18] L.D. Tijing, Y.C. Woo, J.S. Choi, S. Lee, S.H. Kim, H.K. Shon, Fouling and its control in membrane distillation-A review, J. Membr. Sci., 475 (2015) 215-244.

[19] Q.H. She, R. Wang, A.G. Fane, C.Y.Y. Tang, Membrane fouling in osmotically driven membrane processes: A review, J. Membr. Sci., 499 (2016) 201-233. 
[20] M. Baghbanzadeh, D. Rana, C.Q. Lan, T. Matsuura, Zero thermal input membrane distillation, a zero-waste and sustainable solution for freshwater shortage, Appl. Energy, 187 (2017) 910-928.

[21] S. Adham, A. Hussain, J.M. Matar, R. Dores, A. Janson, Application of Membrane Distillation for desalting brines from thermal desalination plants, Desalination, 314 (2013) 101-108.

[22] D. Woldemariam, A. Kullab, U. Fortkamp, J. Magner, H. Royen, A. Martin, Membrane distillation pilot plant trials with pharmaceutical residues and energy demand analysis, Chem. Eng. J., 306 (2016) 471-483.

[23] M. Ren, P. Ning, J. Xu, G. Qu, R. Xie, Concentration and treatment of ceric ammonium nitrate wastewater by integrated electrodialysis-vacuum membrane distillation process, Chem. Eng. J., 351 (2018) 721-731.

[24] H. Ramlow, R.A.F. Machado, C. Marangoni, Direct contact membrane distillation for textile wastewater treatment: a state of the art review, Water Sci. Technol., 76 (2017) 25652579.

[25] P.J. Lin, M.C. Yang, Y.L. Li, J.H. Chen, Prevention of surfactant wetting with agarose hydrogel layer for direct contact membrane distillation used in dyeing wastewater treatment, J. Membr. Sci., 475 (2015) 511-520.

[26] A. Criscuoli, J. Zhong, A. Figoli, M. Carnevale, R. Huang, E. Drioli, Treatment of dye solutions by vacuum membrane distillation, Water Res., 42 (2008) 5031-5037.

[27] F. Banat, S. Al-Asheh, M. Qtaishat, Treatment of waters colored with methylene blue dye by vacuum membrane distillation, Desalination, 174 (2005) 87-96.

[28] R. Baghel, S. Upadhyaya, S.P. Chaurasia, K. Singh, S. Kalla, Optimization of process variables by the application of response surface methodology for naphthol blue black dye removal in vacuum membrane distillation, J. Cleaner Prod., 199 (2018) 900-915. 
[29] A. Criscuoli, M.C. Carnevale, E. Drioli, Evaluation of energy requirements in membrane distillation, Chem. Eng. Process., 47 (2008) 1098-1105.

[30] N. Kuipers, R. van Leerdam, J. van Medevoort, W. van Tongeren, B. Verhasselt, L. Verelst, M. Vermeersch, D. Corbisier, Techno-economic assessment of boiler feed water production by membrane distillation with reuse of thermal waste energy from cooling water, Desalin. Water Treat., 55 (2015) 3506-3518.

[31] A. Jansen, J. Hanemaaijer, J.W. Assink, E.V. Sonsbeek, C. Dotremont, J. Medevoort, Pilot plants prove feasibility of a new desalination technique, 2010.

[32] H.C. Duong, A.R. Chivas, B. Nelemans, M. Duke, S. Gray, T.Y. Cath, L.D. Nghiem, Treatment of RO brine from CSG produced water by spiral-wound air gap membrane distillation - A pilot study, Desalination, 366 (2015) 121-129.

[33] L. Eykens, I. Hitsov, K. De Sitter, C. Dotremont, L. Pinoy, B. Van der Bruggen, Direct contact and air gap membrane distillation: Differences and similarities between lab and pilot scale, Desalination, 422 (2017) 91-100.

[34] S. Sen, G.N. Demirer, Anaerobic treatment of real textile wastewater with a fluidized bed reactor, Water Res., 37 (2003) 1868-1878.

[35] H. Feitkenhauer, U. Meyer, Anaerobic digestion of alcohol sulfate (anionic surfactant) rich wastewater - batch experiments. Part 1: influence of the surfactant concentration, Bioresour. Technol., 82 (2002) 115-121.

[36] S. Leaper, A. Abdel-Karim, B. Faki, J.M. Luque-Alled, M. Alberto, A. Vijayaraghavan, S.M. Holmes, G. Szekely, M.I. Badawy, N. Shokri, P. Gorgojo, Flux-enhanced PVDF mixed matrix membranes incorporating APTS-functionalized graphene oxide for membrane distillation, J. Membr. Sci., 554 (2018) 309-323.

[37] European and National Drinking Water Quality Standards, in, Drinking Water Inspectorate for Northern Ireland, 2016. 
[38] L.M. Camacho, L. Dumee, J.H. Zhang, J.D. Li, M. Duke, J. Gomez, S. Gray, Advances in Membrane Distillation for Water Desalination and Purification Applications, Water, 5 (2013) 94-196.

[39] J.F. Li, J. Wu, H.F. Sun, F.Q. Cheng, Y. Liu, Advanced treatment of biologically treated coking wastewater by membrane distillation coupled with pre-coagulation, Desalination, 380 (2016) 43-51.

[40] A.M. Alklaibi, N. Lior, Comparative study of direct-contact and air-gap membrane distillation processes, Industrial \& Engineering Chemistry Research, 46 (2007) 584-590.

[41] H.J. Hwang, K. He, S. Gray, J.H. Zhang, I.S. Moon, Direct contact membrane distillation (DCMD): Experimental study on the commercial PTFE membrane and modeling, J. Membr. Sci., 371 (2011) 90-98.

[42] D. Singh, K.K. Sirkar, Desalination of brine and produced water by direct contact membrane distillation at high temperatures and pressures, J. Membr. Sci., 389 (2012) 380388.

[43] A.M. Alklaibi, N. Lior, Heat and mass transfer resistance analysis of membrane distillation, J. Membr. Sci., 282 (2006) 362-369.

[44] G.W. Meindersma, C.M. Guijt, A.B. de Haan, Water recycling and desalination by air gap membrane distillation, Environmental Progress, 24 (2005) 434-441.

[45] M.I. Rakib, R. Saidur, E.N. Mohamad, A.M. Afifi, Waste-heat utilization - The sustainable technologies to minimize energy consumption in Bangladesh textile sector, J. Cleaner Prod., 142 (2017) 1867-1876.

[46] A. Zarebska, D.R. Nieto, K.V. Christensen, B. Norddahl, Ammonia recovery from agricultural wastes by membrane distillation: Fouling characterization and mechanism, Water Res., 56 (2014) 1-10. 
[47] Z.L. Xie, T. Duong, M. Hoang, C. Nguyen, B. Bolto, Ammonia removal by sweep gas membrane distillation, Water Res., 43 (2009) 1693-1699.

[48] X. Yang, H.J. Pang, J.H. Zhang, A. Liubinas, M. Duke, Sustainable waste water deammonification by vacuum membrane distillation without $\mathrm{pH}$ adjustment: Role of water chemistry, Chem. Eng. J., 328 (2017) 884-893.

[49] C.A. Quist-Jensen, F. Macedonio, D. Horbez, E. Drioli, Reclamation of sodium sulfate from industrial wastewater by using membrane distillation and membrane crystallization, Desalination, 401 (2017) 112-119.

[50] M. Xie, L.D. Nghiem, W.E. Price, M. Elimelech, Toward Resource Recovery from Wastewater: Extraction of Phosphorus from Digested Sludge Using a Hybrid Forward Osmosis-Membrane Distillation Process, Environ. Sci. Technol. Lett., 1 (2014) 191-195.

[51] K.L. Hickenbottom, T.Y. Cath, Sustainable operation of membrane distillation for enhancement of mineral recovery from hypersaline solutions, J. Membr. Sci., 454 (2014) 426-435.

[52] C.A. Quist-Jensen, A. Ali, S. Mondal, F. Macedonio, E. Drioli, A study of membrane distillation and crystallization for lithium recovery from high-concentrated aqueous solutions, J. Membr. Sci., 505 (2016) 167-173.

[53] A. Alkhudhiri, N. Darwish, N. Hilal, Produced water treatment: Application of Air Gap Membrane Distillation, Desalination, 309 (2013) 46-51.

[54] A. Alkhudhiri, N. Hilal, Air gap membrane distillation: A detailed study of high saline solution, Desalination, 403 (2017) 179-186.

[55] J.A. Sanmartino, M. Khayet, M.C. Garcia-Payo, H. El Bakouri, A. Riaza, Desalination and concentration of saline aqueous solutions up to supersaturation by air gap membrane distillation and crystallization fouling, Desalination, 393 (2016) 39-51. 
[56] A.K. An, J. Guo, S. Jeong, E.-J. Lee, S.A.A. Tabatabai, T. Leiknes, High flux and antifouling properties of negatively charged membrane for dyeing wastewater treatment by membrane distillation, Water Res., 103 (2016) 362-371.

[57] N.M. Mokhtar, W.J. Lau, A.F. Ismail, Dye wastewater treatment by direct contact membrane distillation using polyvinylidene fluoride hollow fiber membranes, J. Polym. Eng., 35 (2015) 471-479.

[58] N.M. Molehtar, W.J. Lau, A.F. Ismail, S. Kartohardjono, S.O. Lai, H.C. Teoh, The potential of direct contact membrane distillation for industrial textile wastewater treatment using PVDF-Cloisite 15A nanocomposite membrane, Chem. Eng. Res. Des., 111 (2016) 284293.

[59] J.V. Garcia, N. Dow, N. Milne, J.H. Zhang, L. Naidoo, S. Gray, M. Duke, Membrane Distillation Trial on Textile Wastewater Containing Surfactants Using Hydrophobic and Hydrophilic-Coated Polytetrafluoroethylene (PTFE) Membranes, Membranes, 8 (2018) 15. [60] A.K. An, J.X. Guo, E.J. Lee, S. Jeong, Y.H. Zhao, Z.K. Wang, T. Leiknes, PDMS/PVDF hybrid electrospun membrane with superhydrophobic property and drop impact dynamics for dyeing wastewater treatment using membrane distillation, J. Membr. Sci., 525 (2017) 57-67.

[61] S.H. Lin, S. Nejati, C. Boo, Y.X. Hu, C.O. Osuji, M. Ehmelech, Omniphobic Membrane for Robust Membrane Distillation, Environ. Sci. Technol. Lett., 1 (2014) 443-447.

\section{Highlights}

4. Synthetic textile wastewater was purified by air gap membrane distillation (AGMD)

5. AGMD simultaneously removed all salts, surfactants and dyes in a single process

6. Permeate quality remained high after 70 hours of continuous testing 


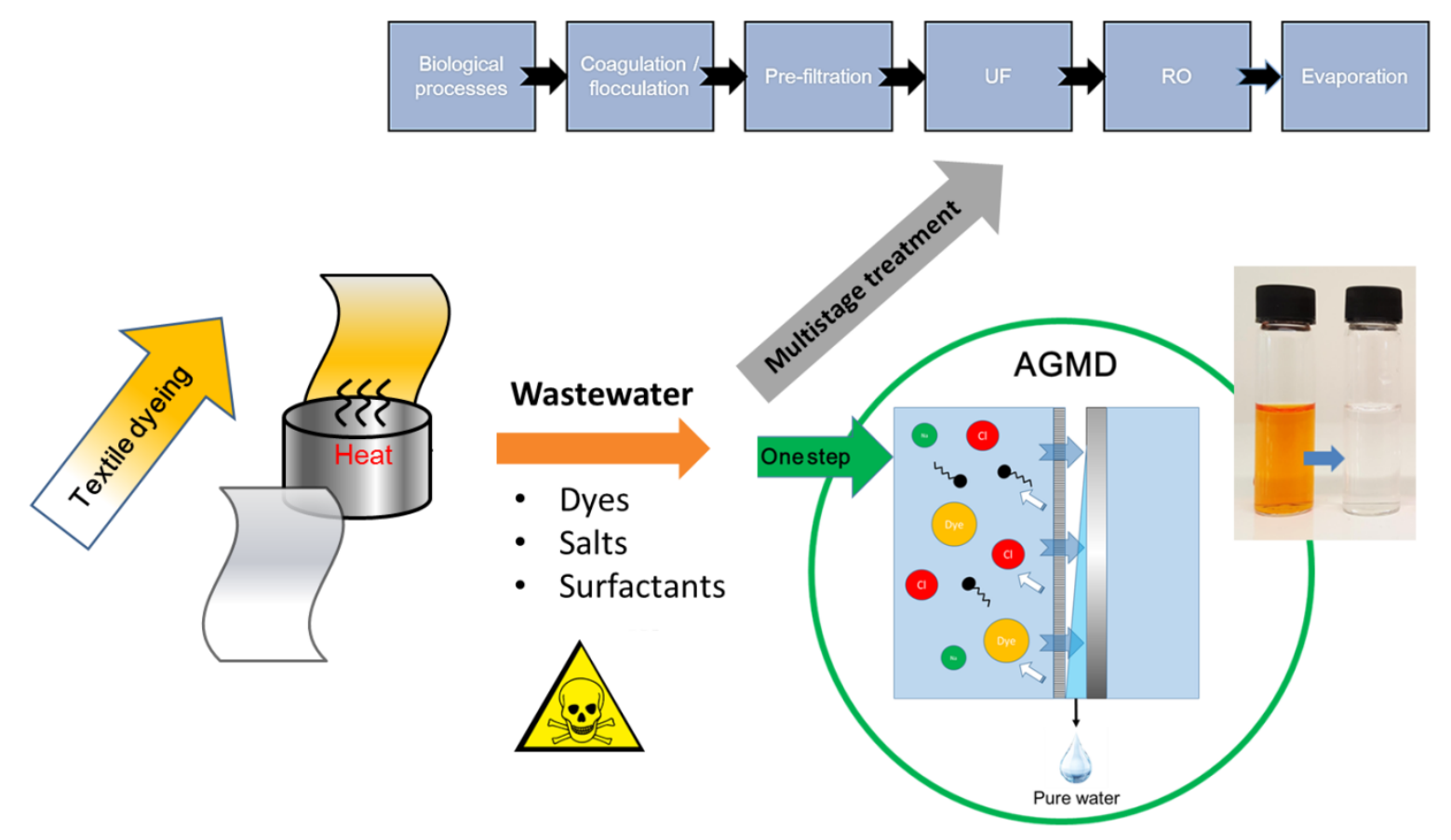

